\title{
ASTROPHYSICAL CONSTRAINTS ON MASSIVE UNSTABLE NEUTRAL RELIC PARTICLES
}

\author{
John Ellis \\ Theoretical Physics Division - CERN \\ 1211 - Geneva 23, Switzerland \\ G.B. Gelmini \\ Department of Physics, University of California \\ Los Angeles, CA 90024-1547, U.S.A. \\ Jorge L. Lopez ${ }^{1)}$ and D.V. Nanopoulos ${ }^{2}$ ) \\ Center for Theoretical Physics, Department of Physics \\ Texas A \& M University \\ College Station, TX 77843-4242, U.S.A. \\ and \\ Astroparticle Physics Group \\ Houston Advanced Research Center (HARC) \\ The Woodlands, TX 77381, U.S.A. \\ Subir Sarkar \\ Department of Theoretical Physics \\ University of Oxford \\ Oxford OX1 3NP, England
}

\begin{abstract}
There has recently been renewed interest in massive neutral dark matter particle candidates with masses greater than $\sim 1 \mathrm{TeV}$ which may be unstable. We reevaluate the constraints on such particles from the possible effects of their decays on the spectrum of the microwave background radiation and the primordially synthesised abundances of the light elements, from observations of the diffuse gamma-ray background radiation, and from searches for muons and neutrinos in nucleon decay and cosmic ray detectors. We find that such unstable neutral relics may well have the cosmological critical density if their lifetime exceeds $\sim 10^{16} \mathrm{yr}$. We illustrate our arguments by applying them to technicolour baryons and to 'cryptons' in superstring-inspired models.
\end{abstract}

ACT-24

CERN-TH-5853/90

CTP-TAMU-96/90

December 1990

1) Supported by an ICSC-World Laboratory Scholarship.

2) Supported in part by DOE Grant DE-FG05-91-ER-40633. 

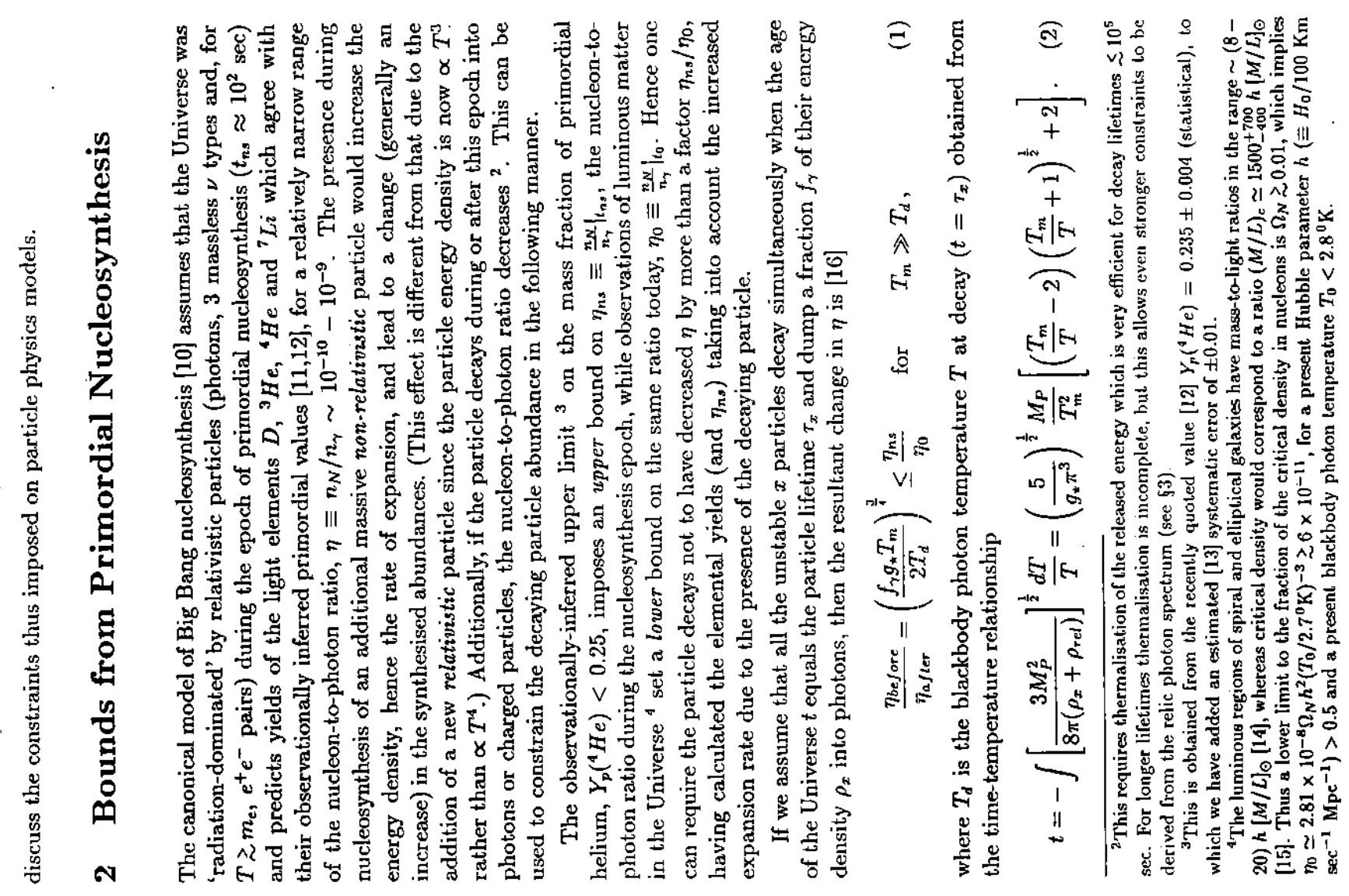

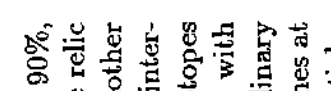
21.

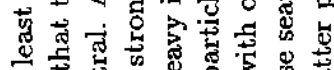

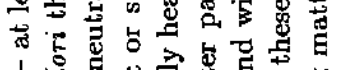

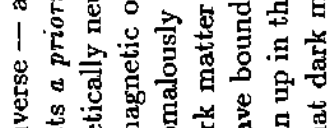

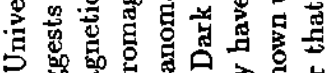

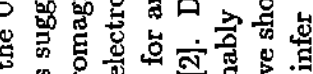

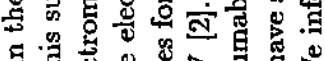

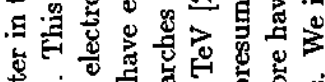

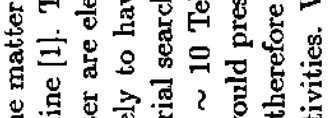

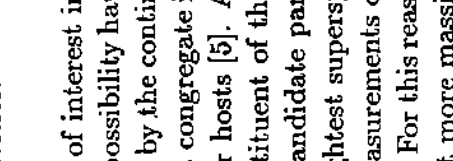

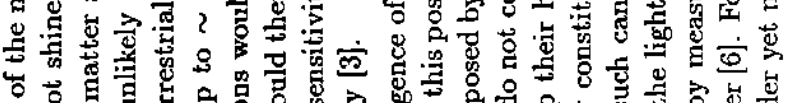

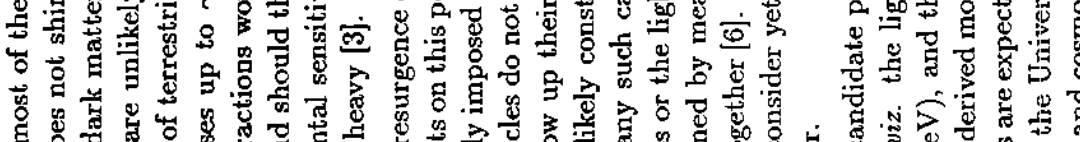

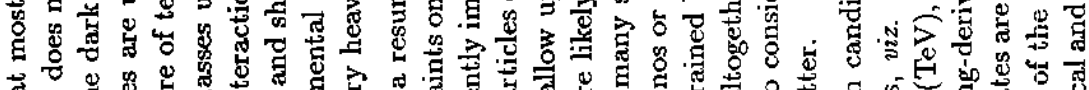

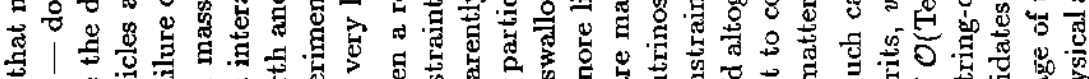

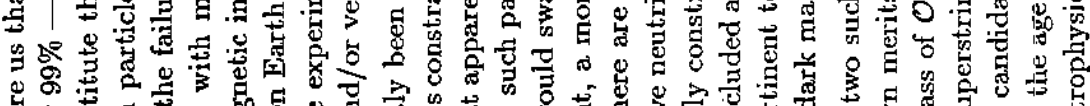

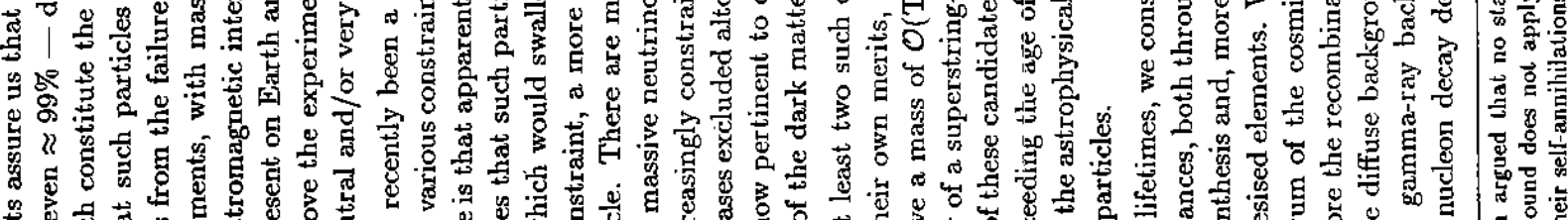

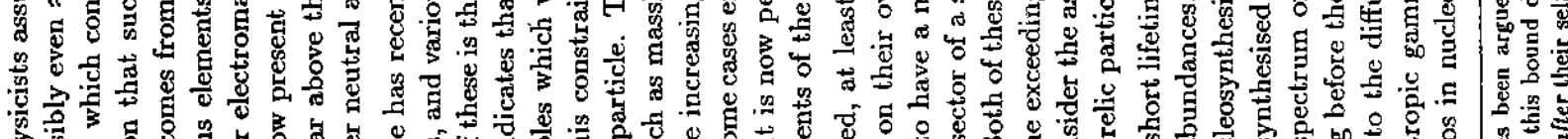

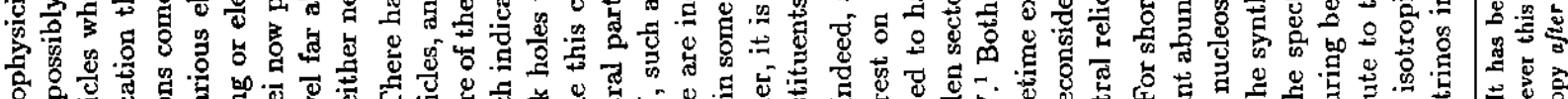

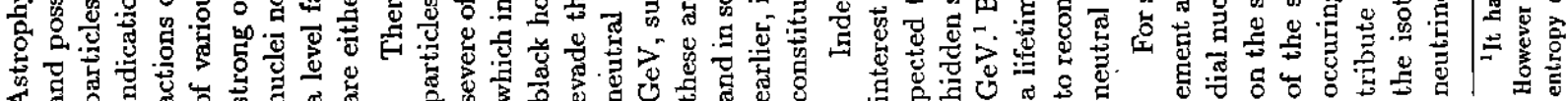




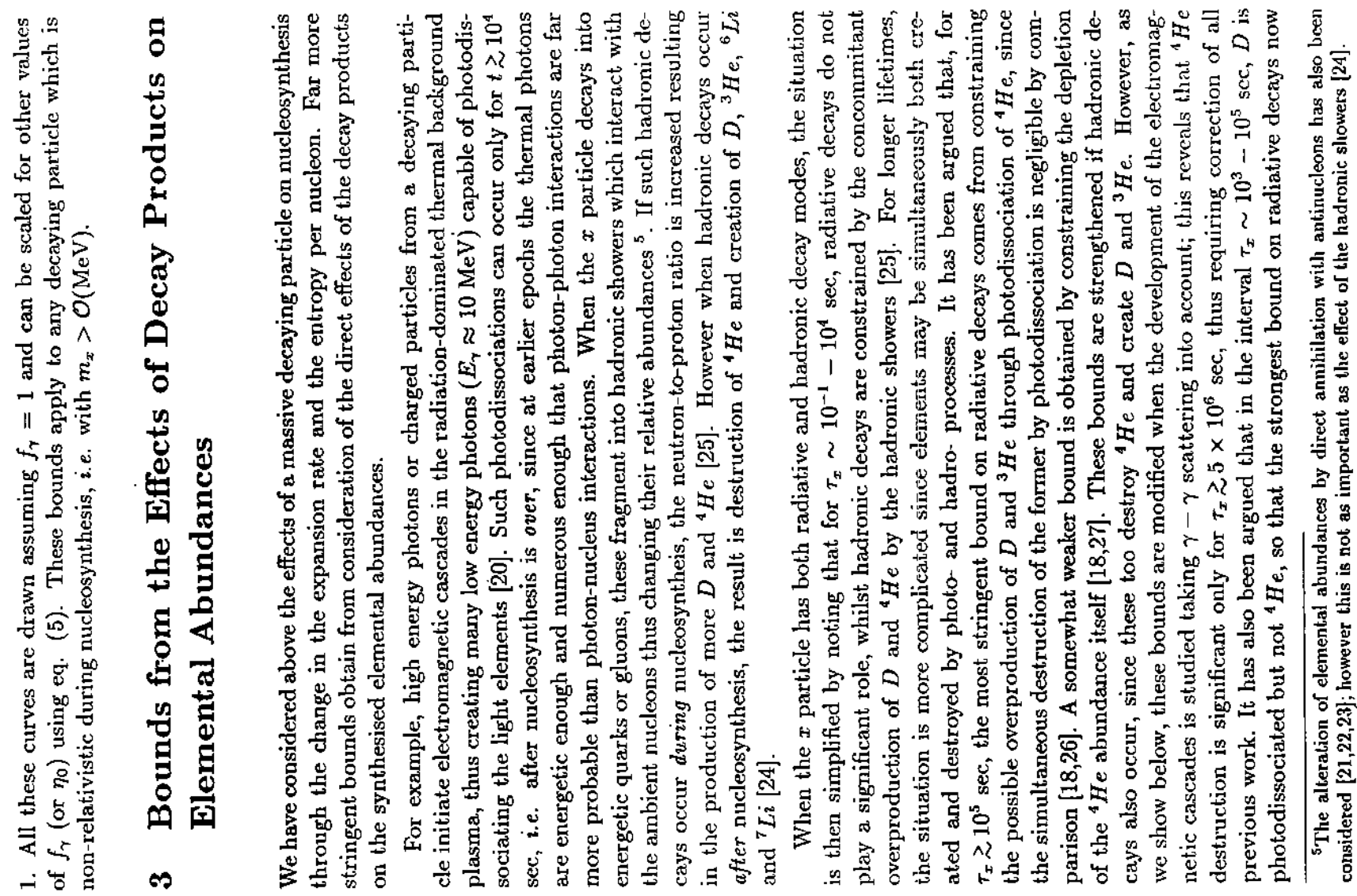

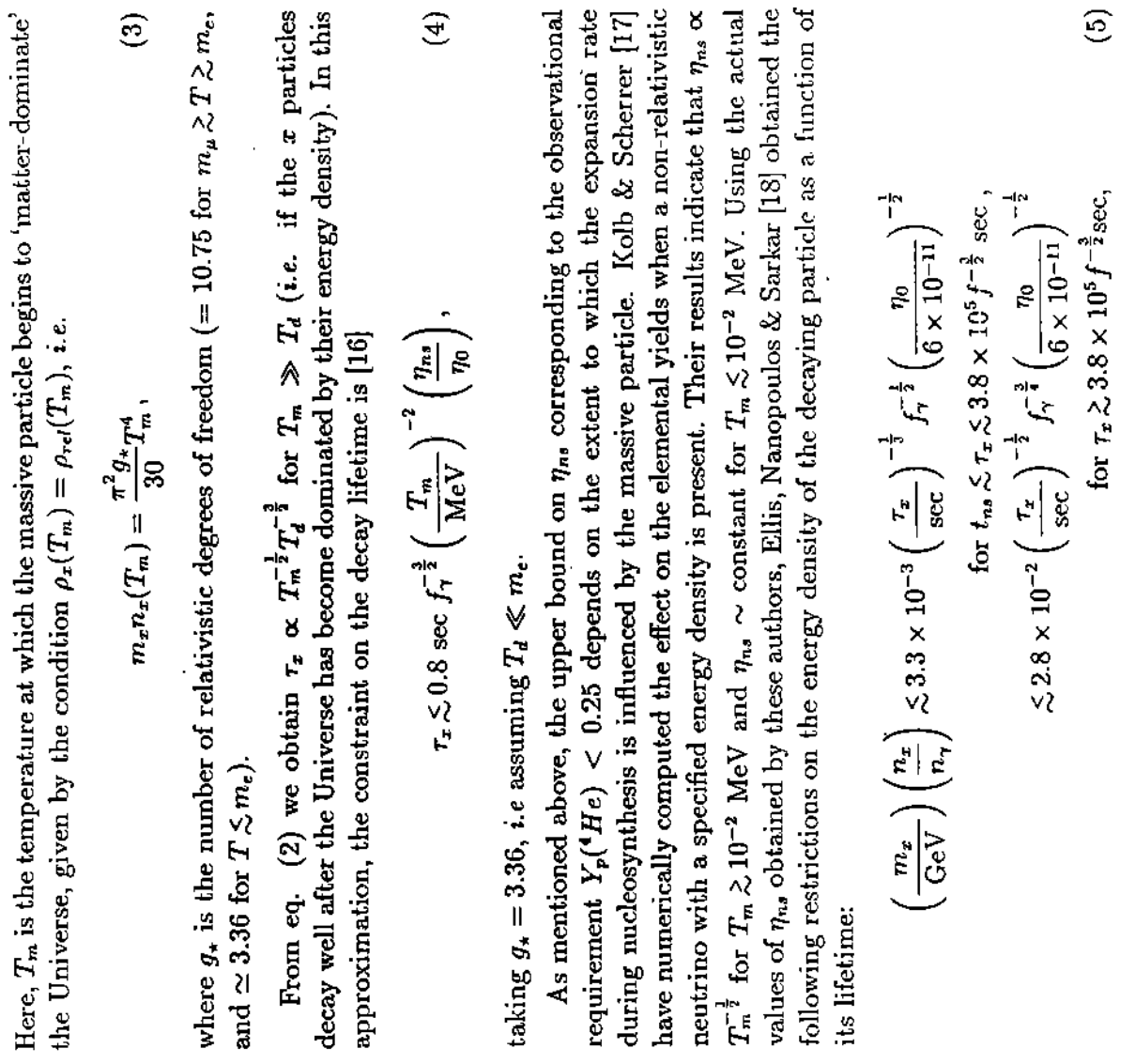

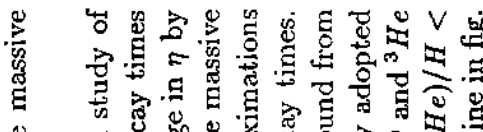

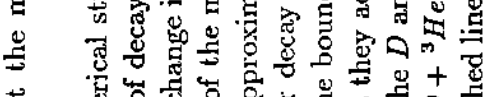

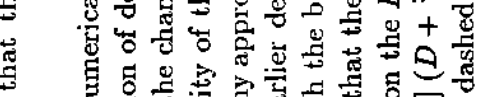

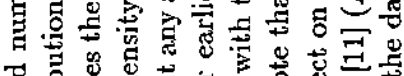

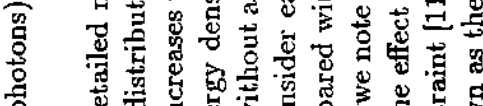

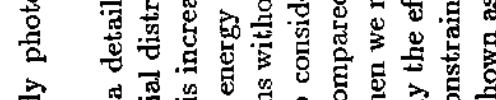
象

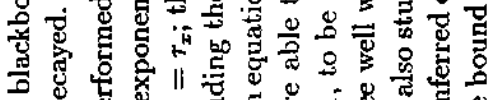

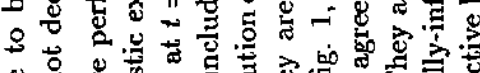

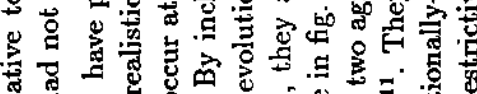
近

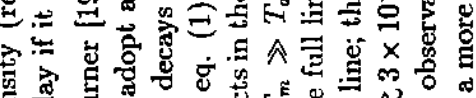

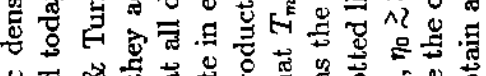

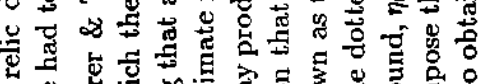

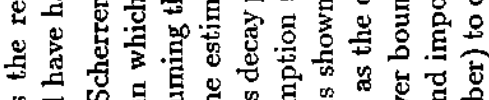

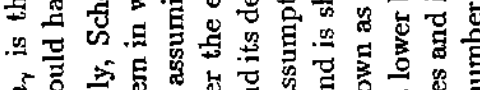

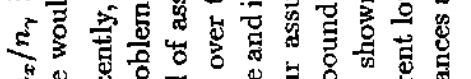

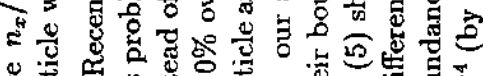

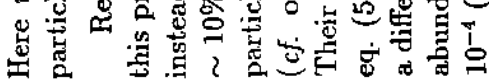




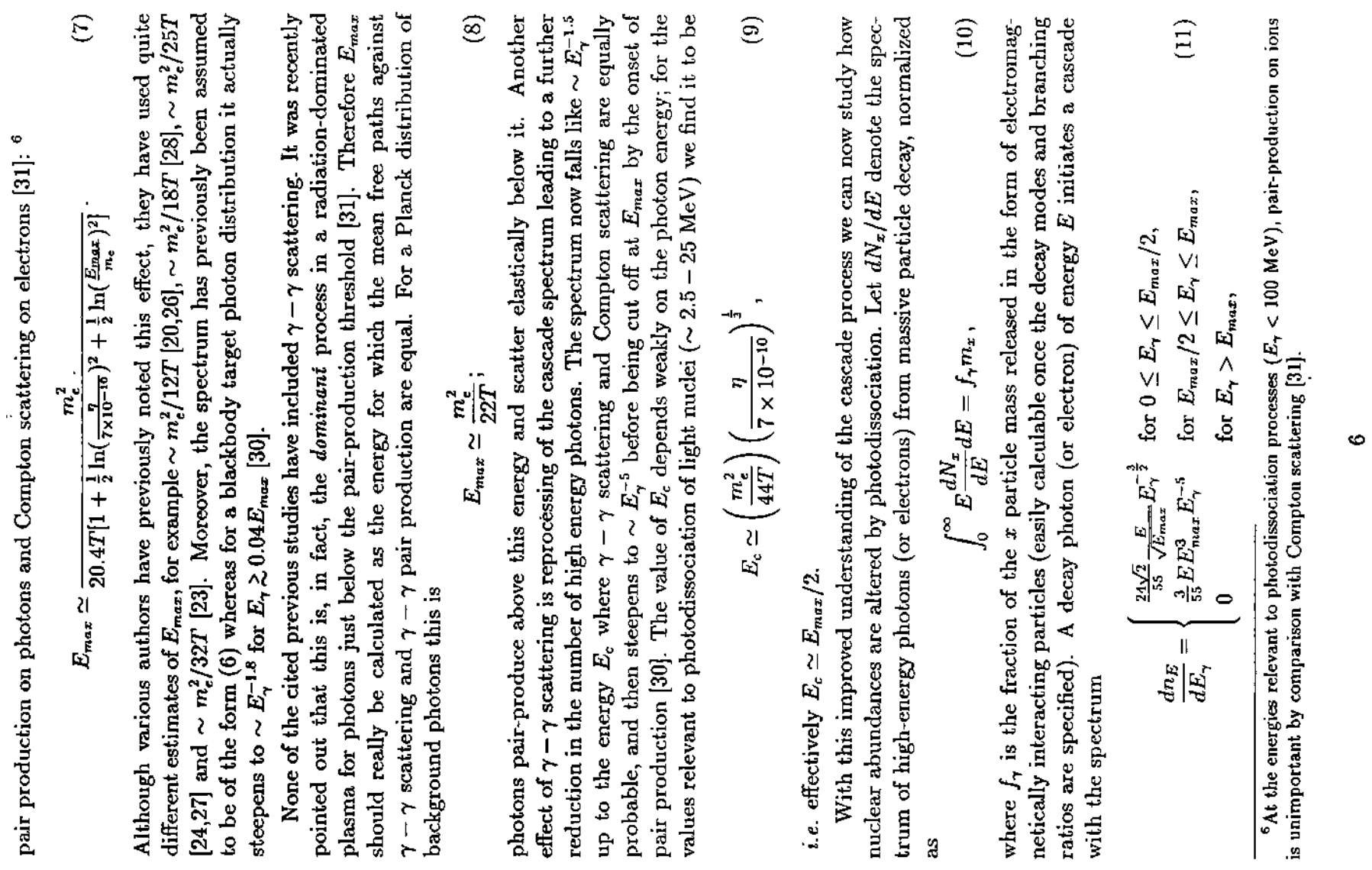

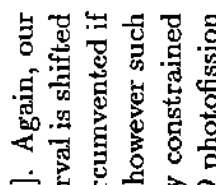

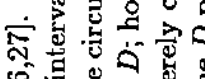

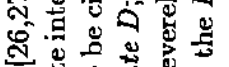

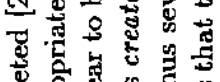

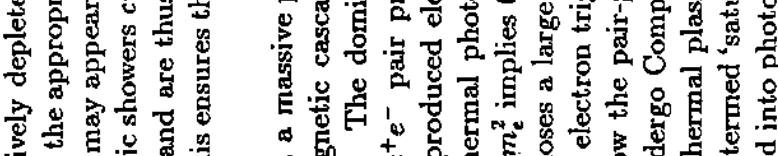

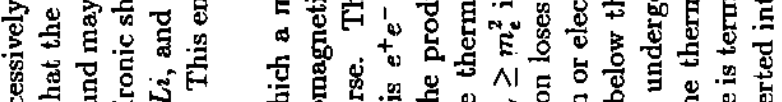

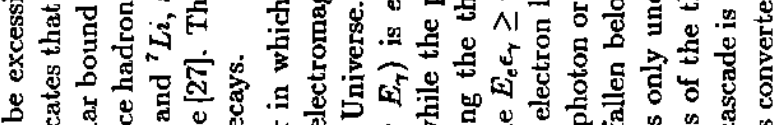

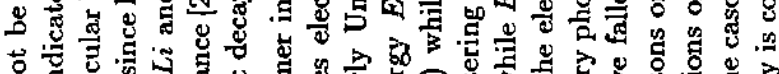

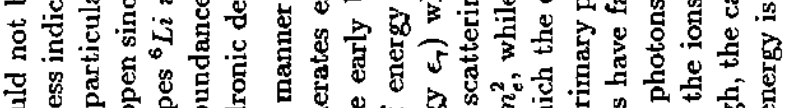

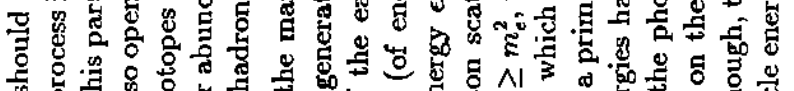

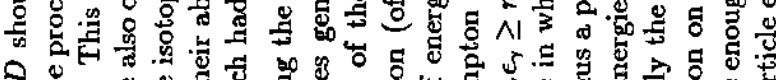

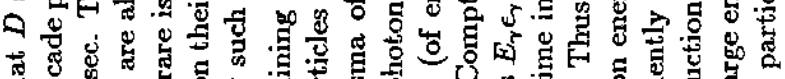

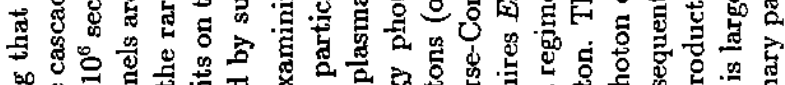

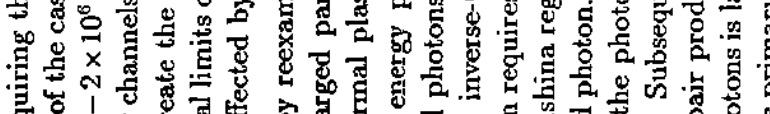

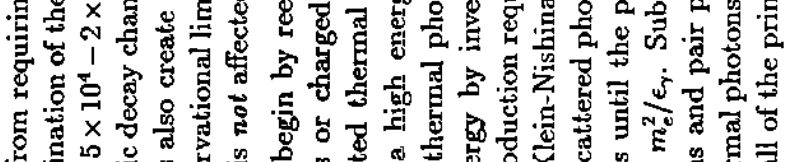

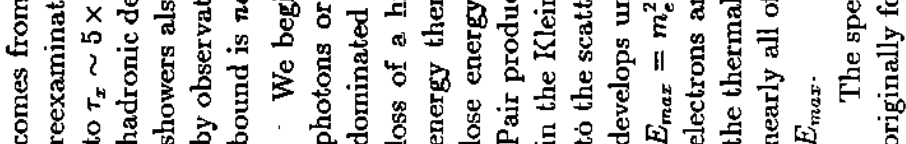

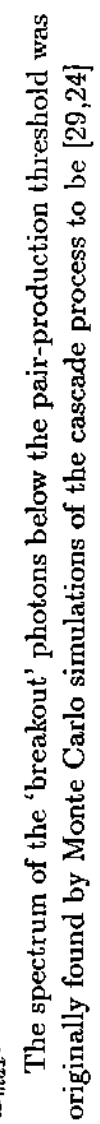

อ

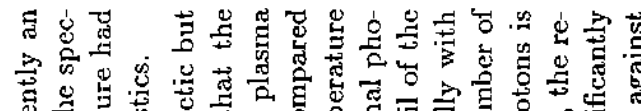

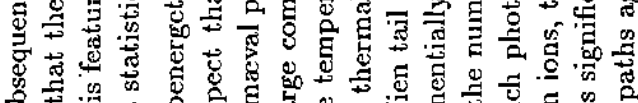

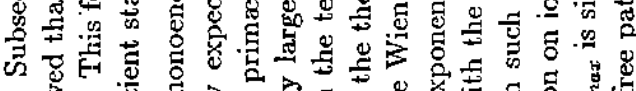

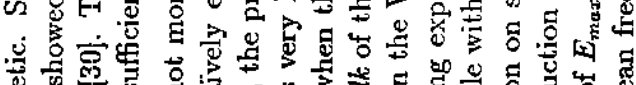

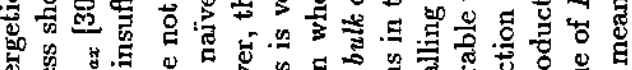

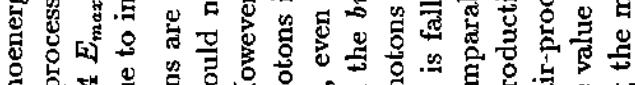

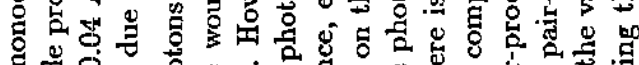

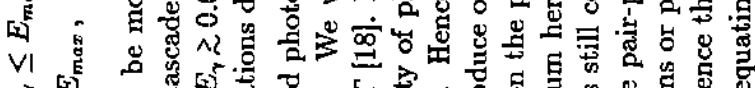

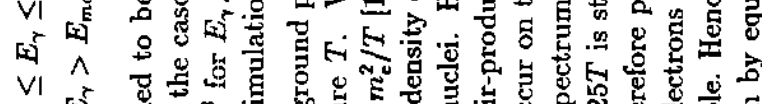

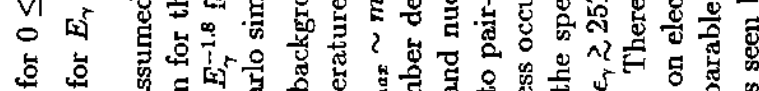
m

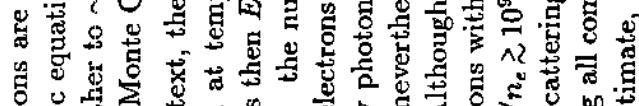

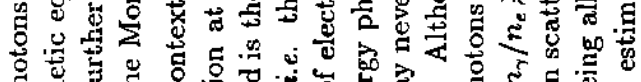

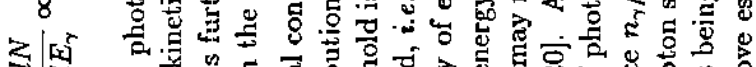

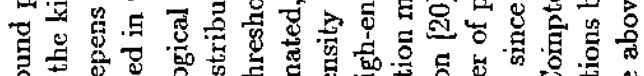

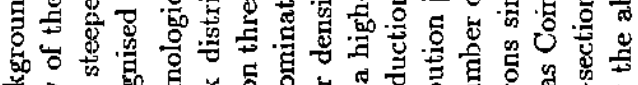

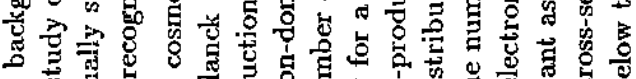

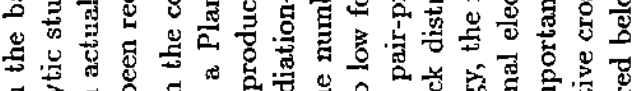

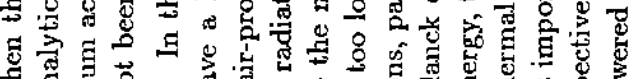




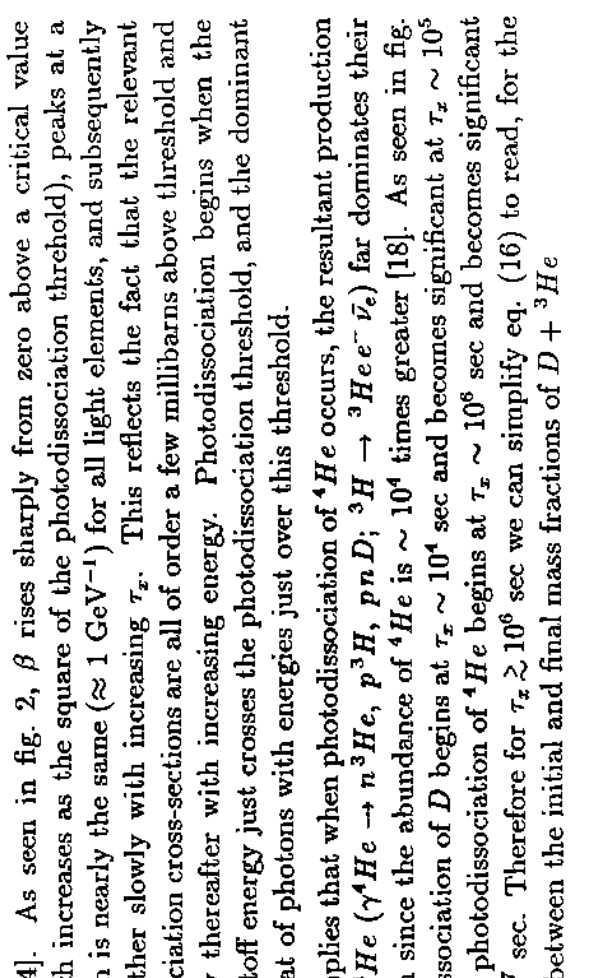

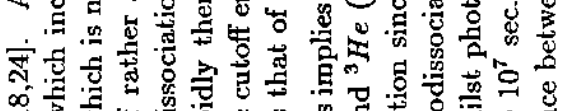

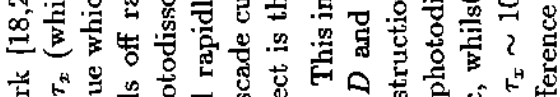

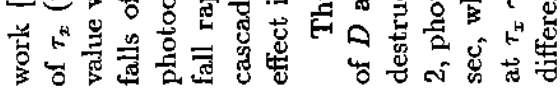

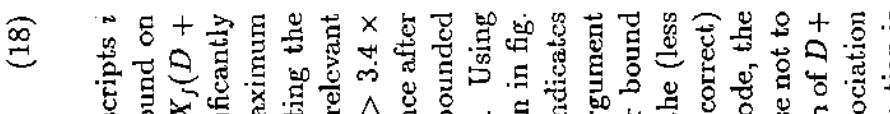

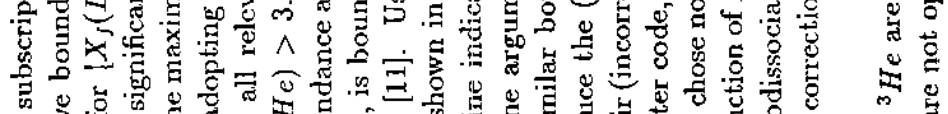

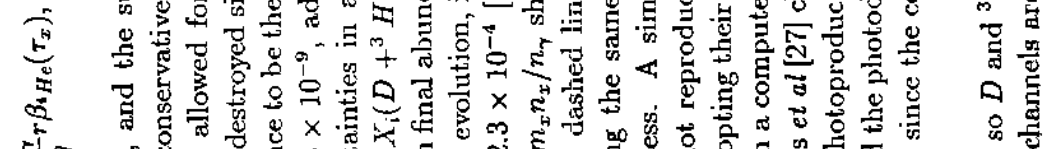
री=

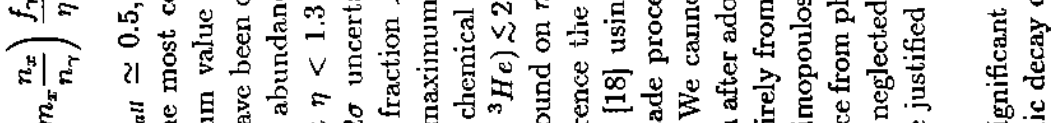
ह

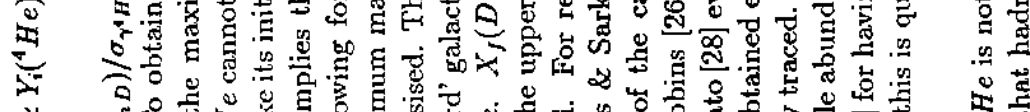
年

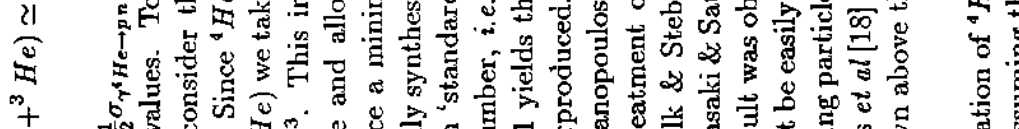
+

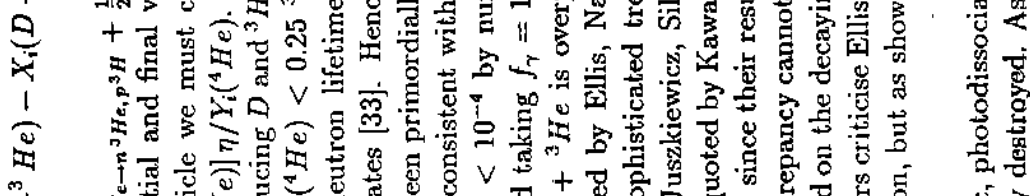
年

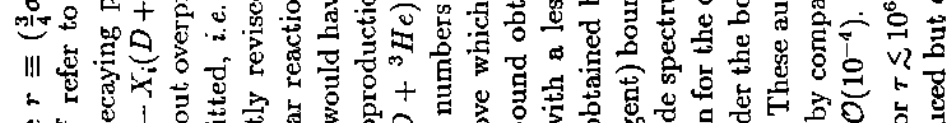
等

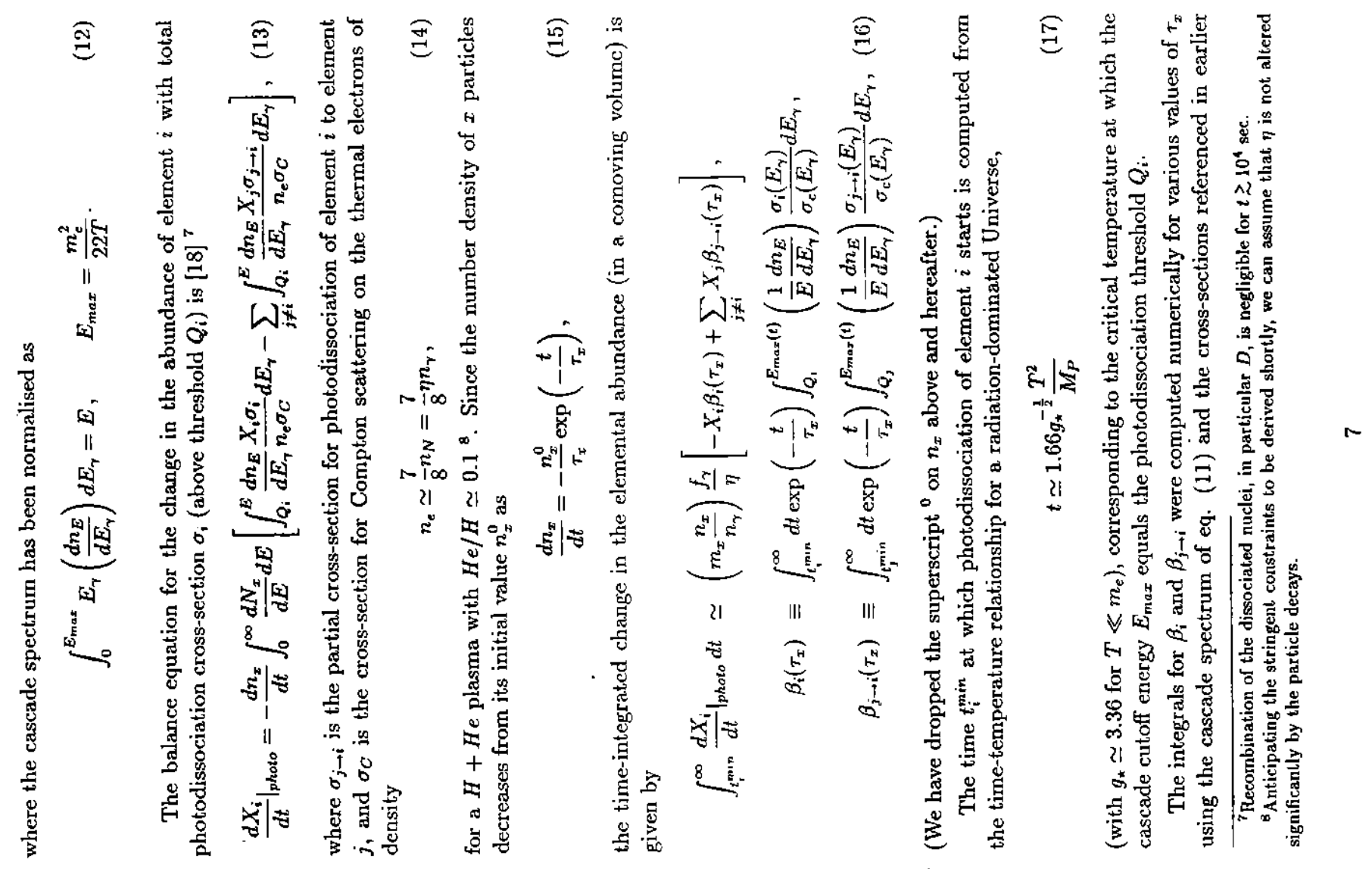




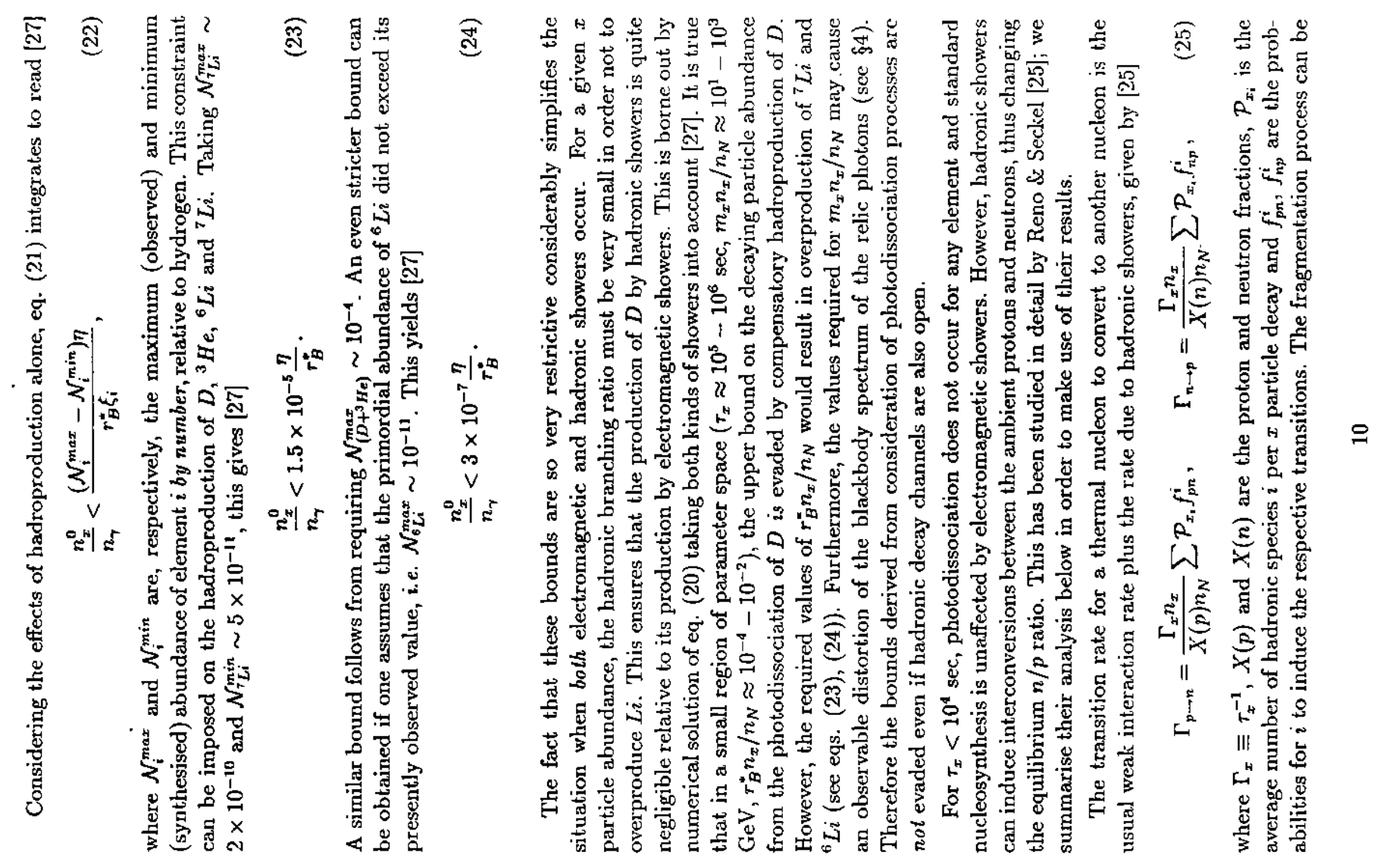

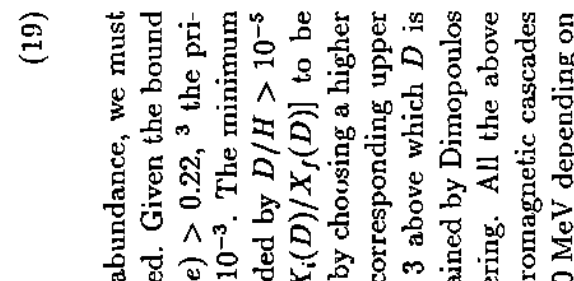

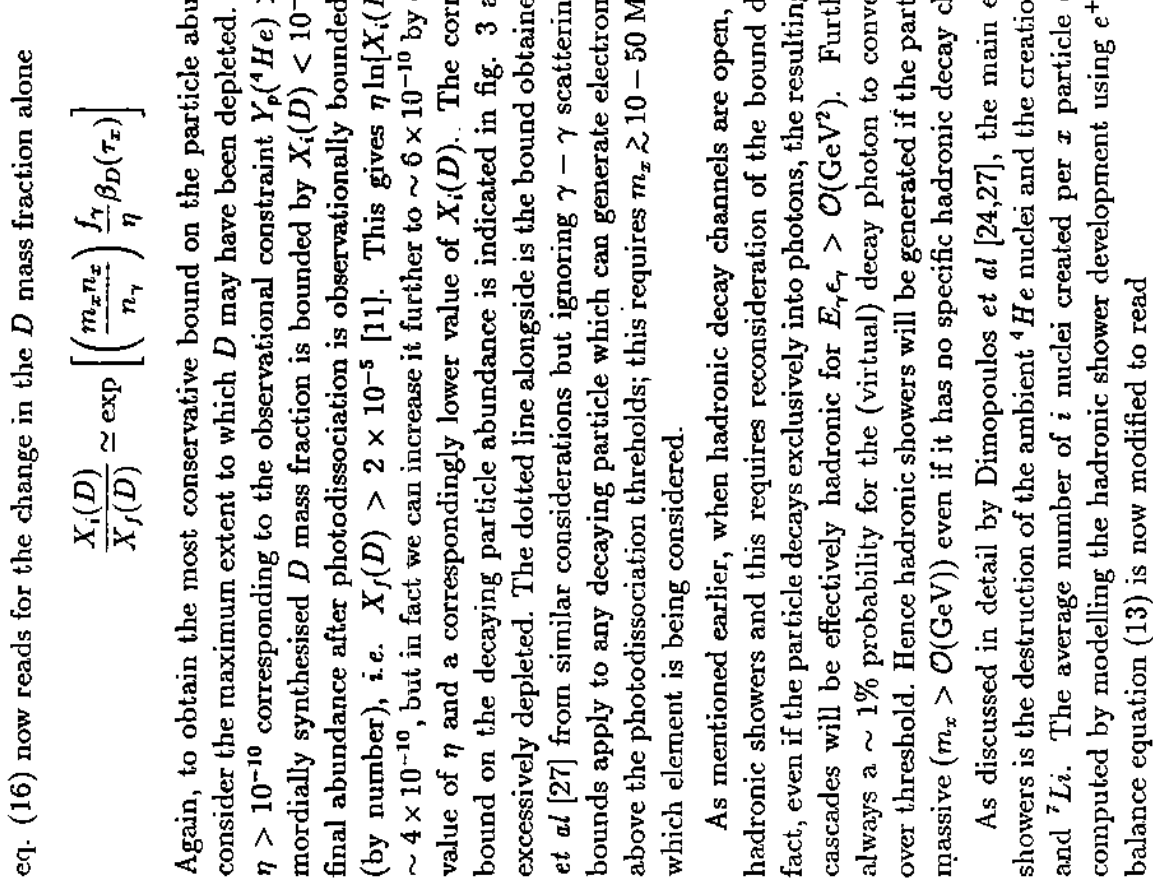

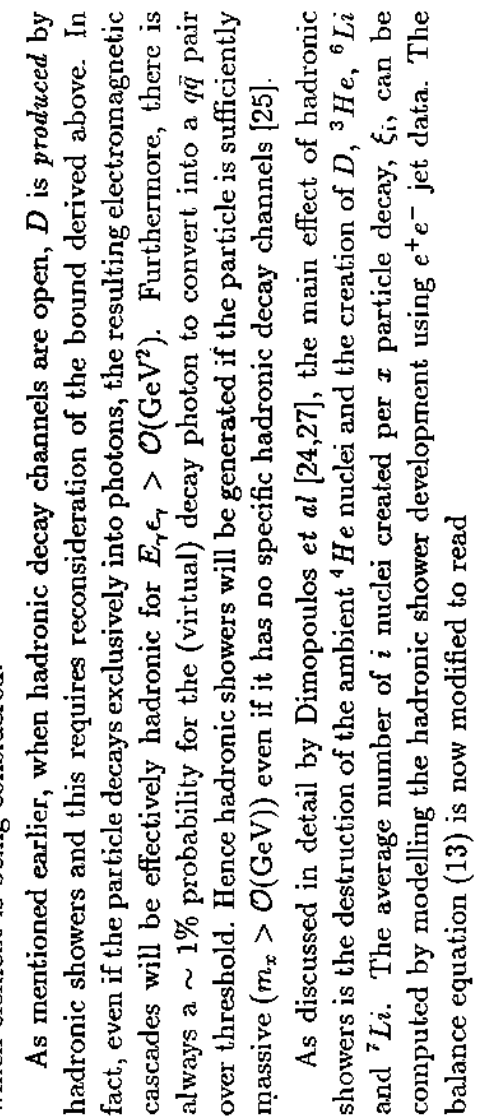

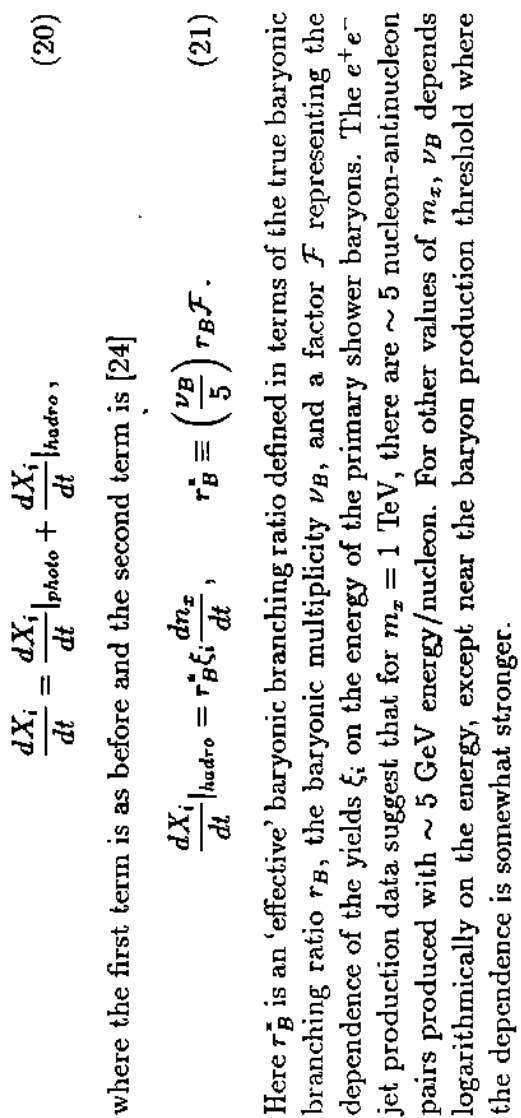



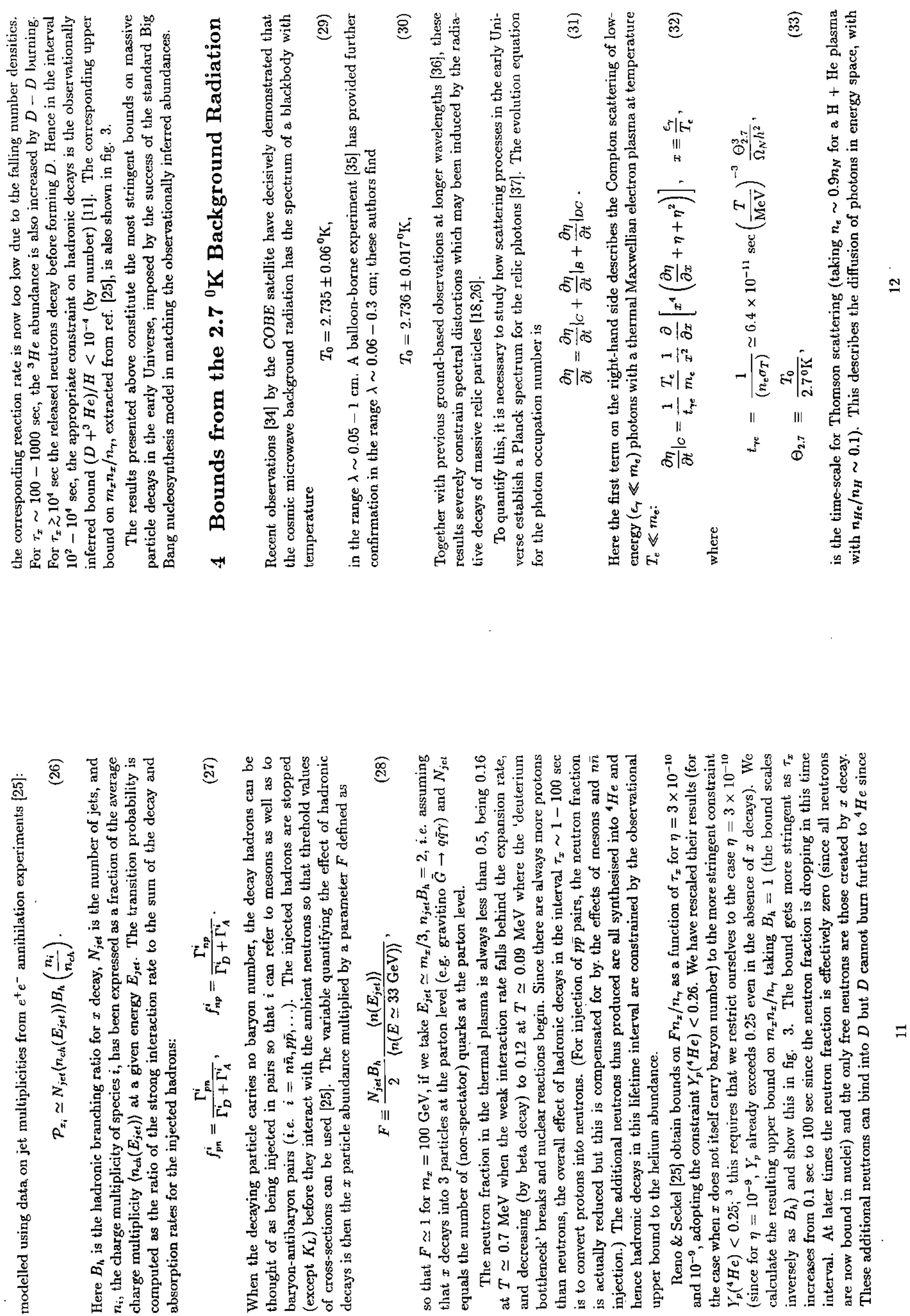


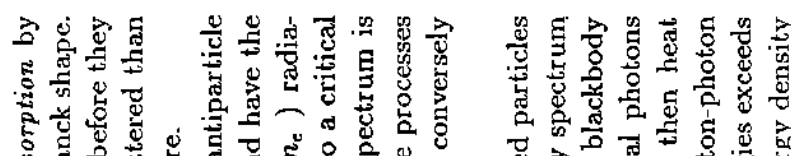
M

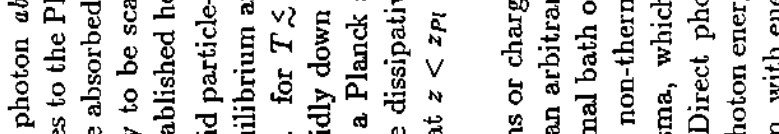

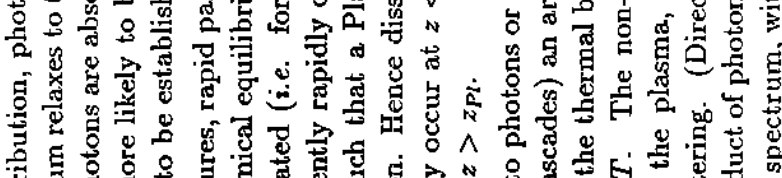
MY WV MIM In -1) W M M Mํ. In: Mํ. W MIn When
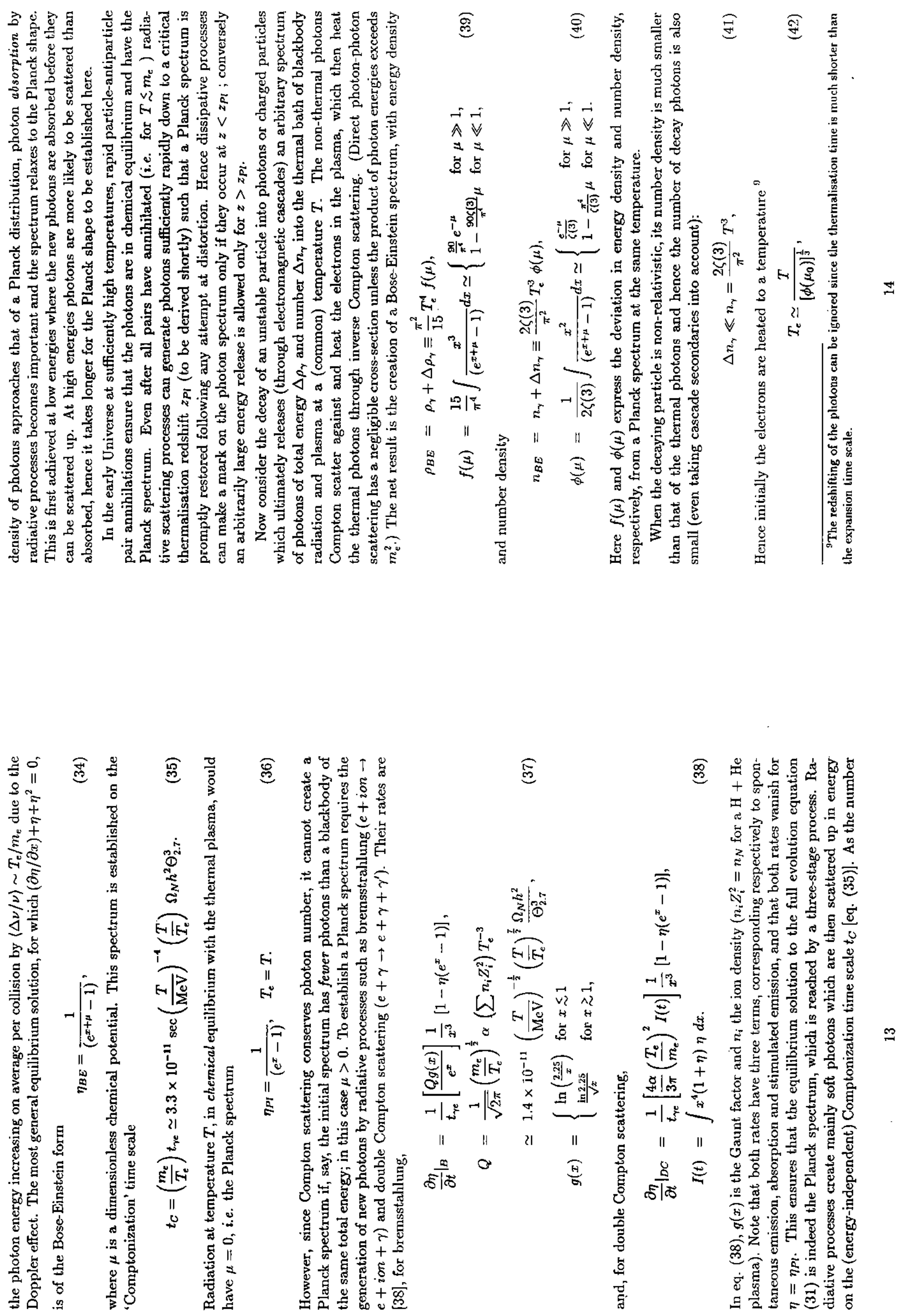


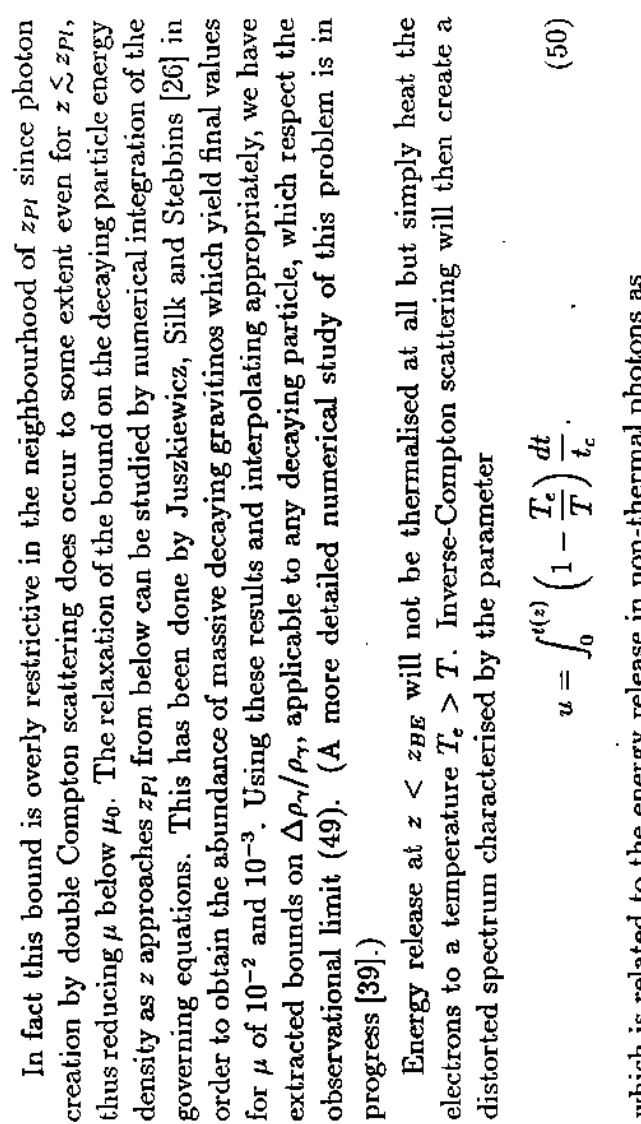

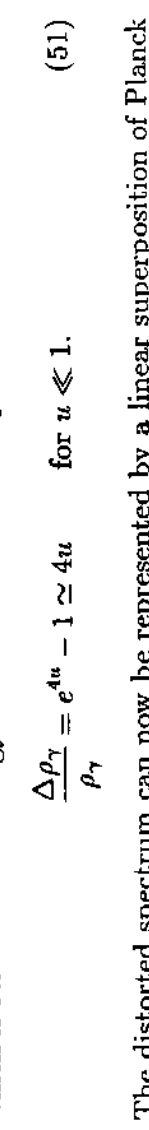

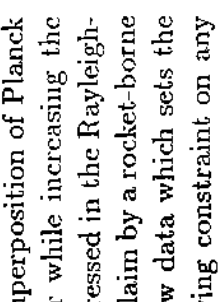

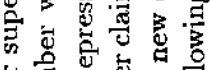

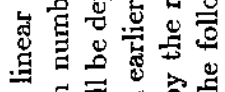

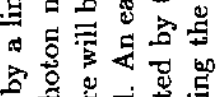

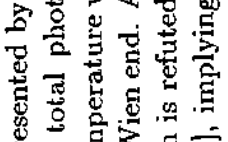

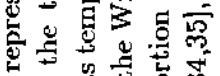

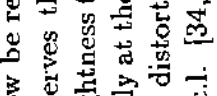

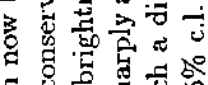

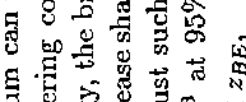

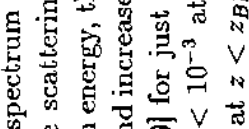

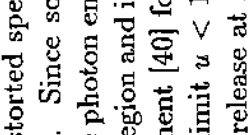

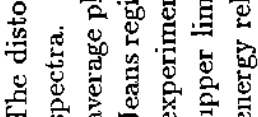

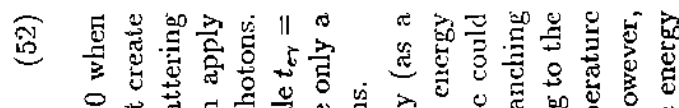

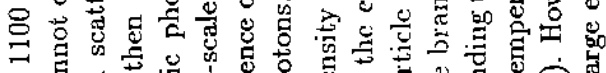

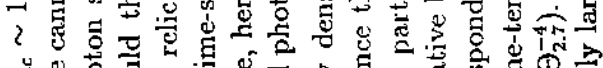
今。

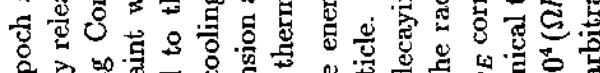

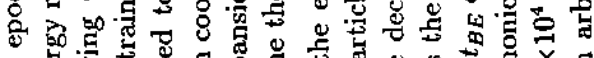
5

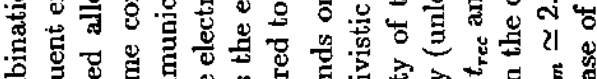

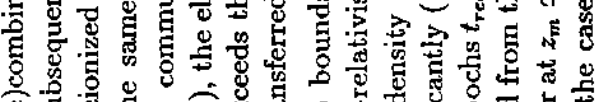
b s.

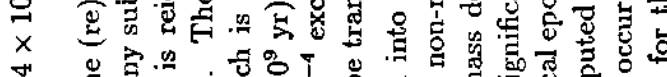

$\checkmark$ V

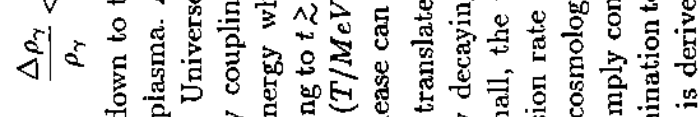

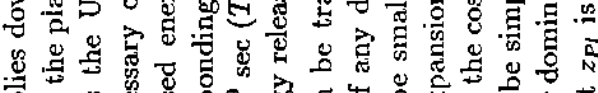

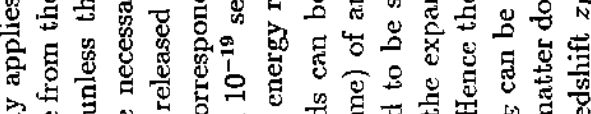

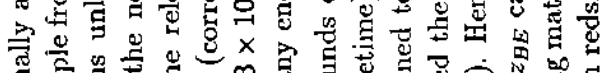

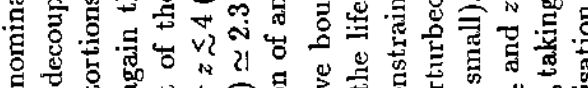

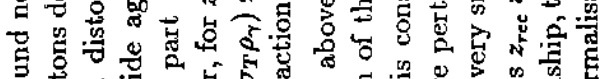

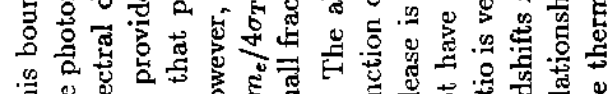

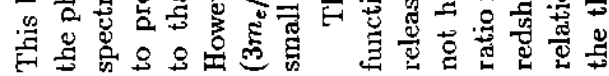

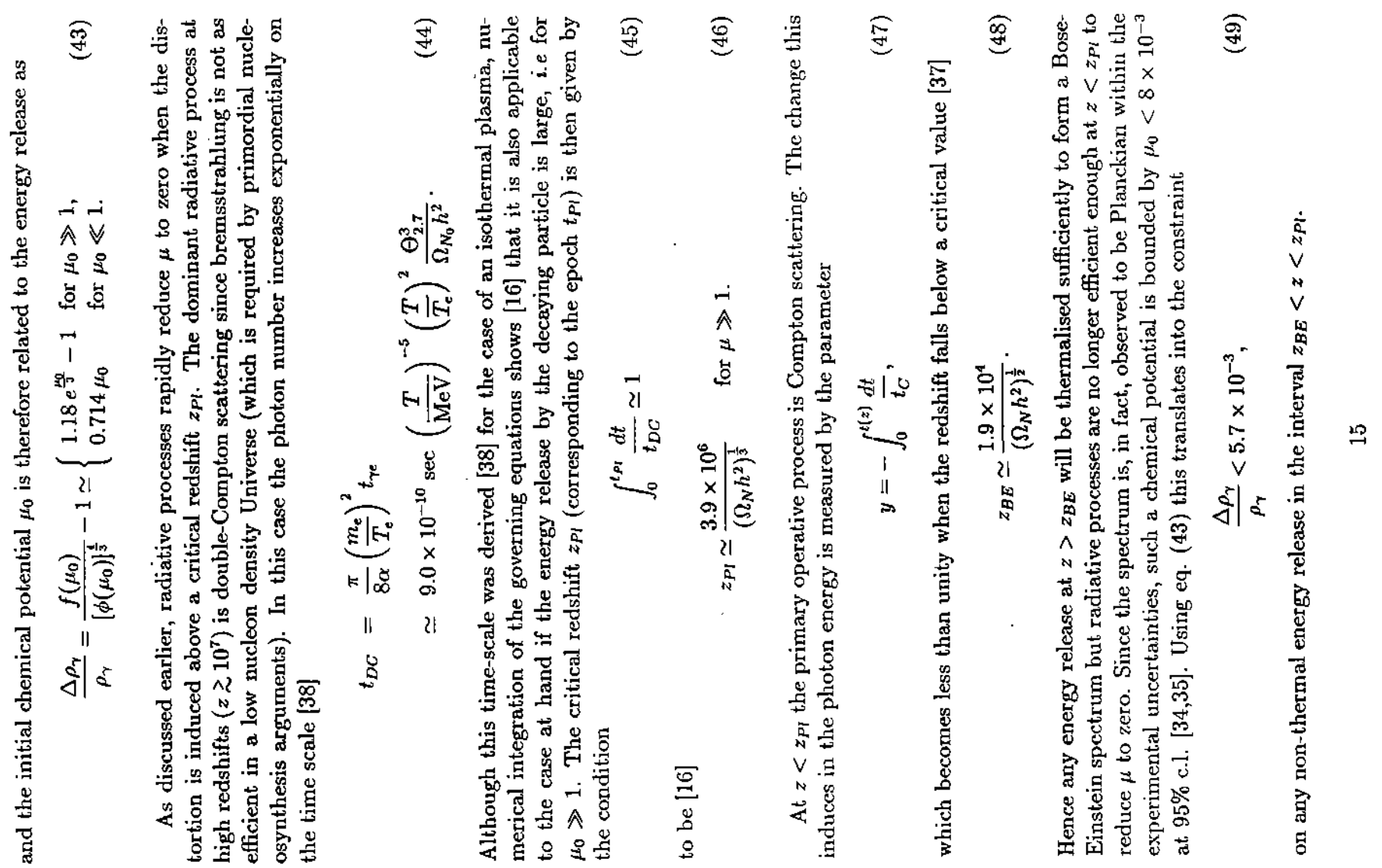



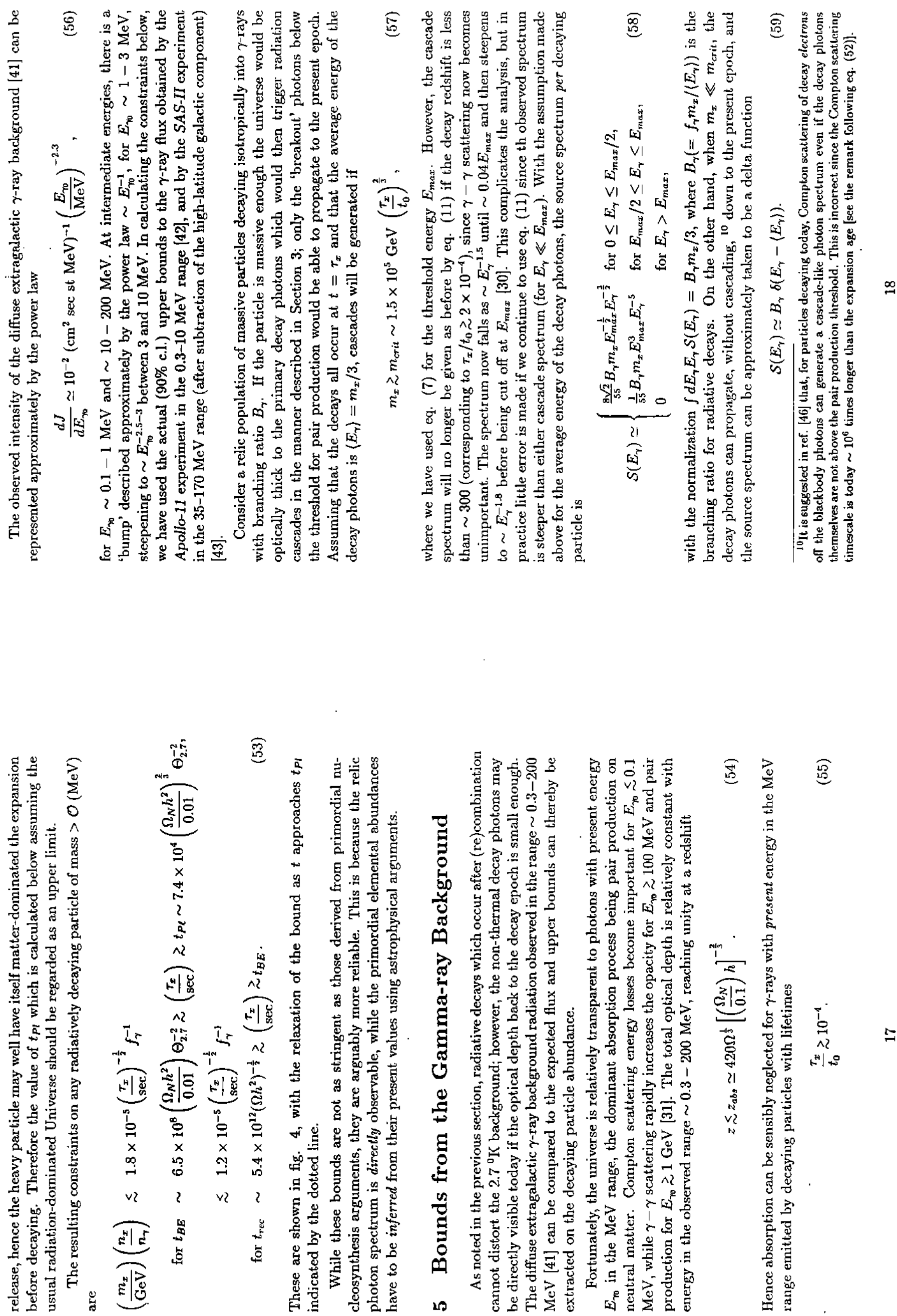


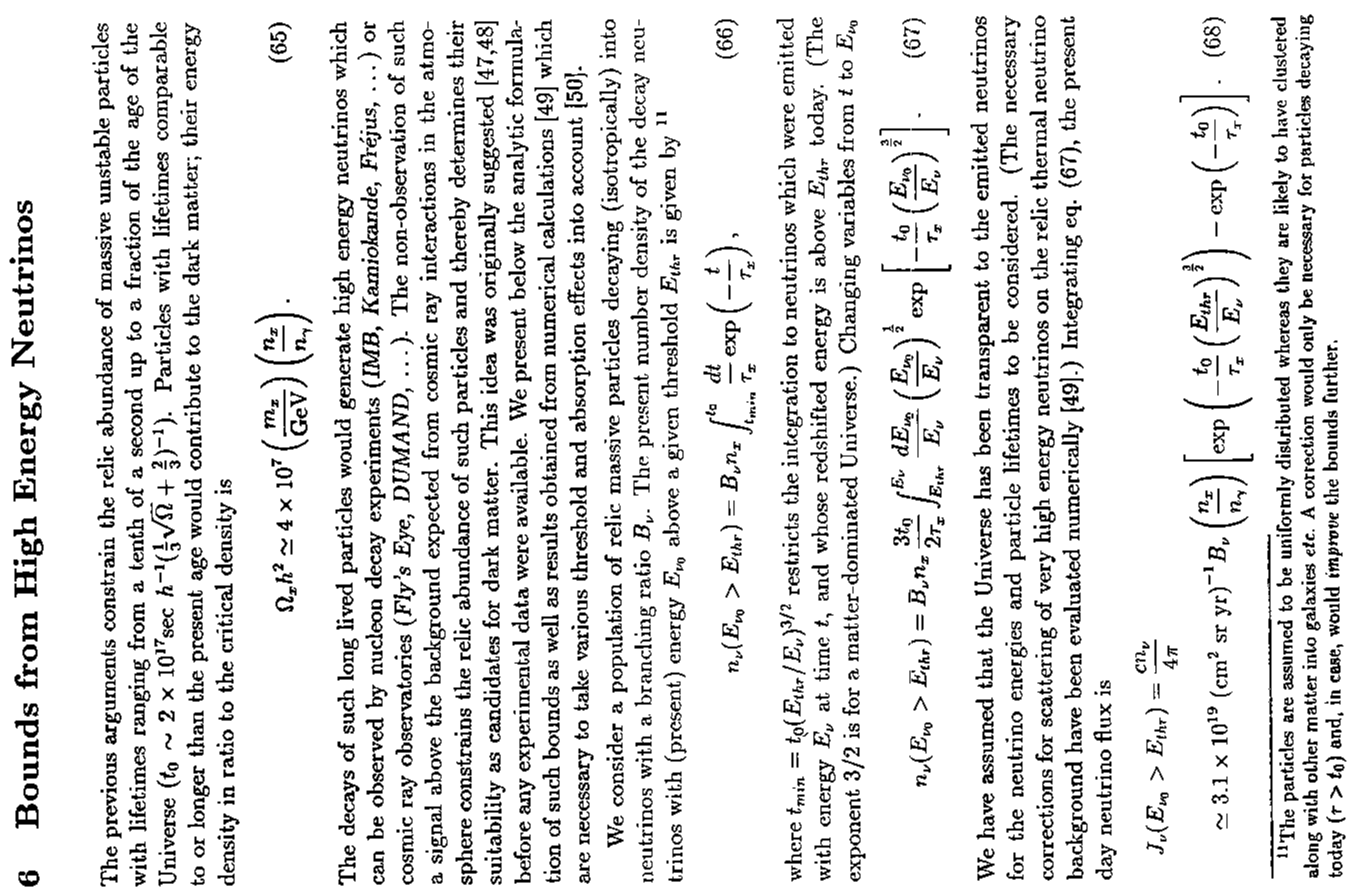

ิ

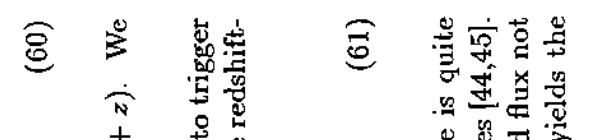

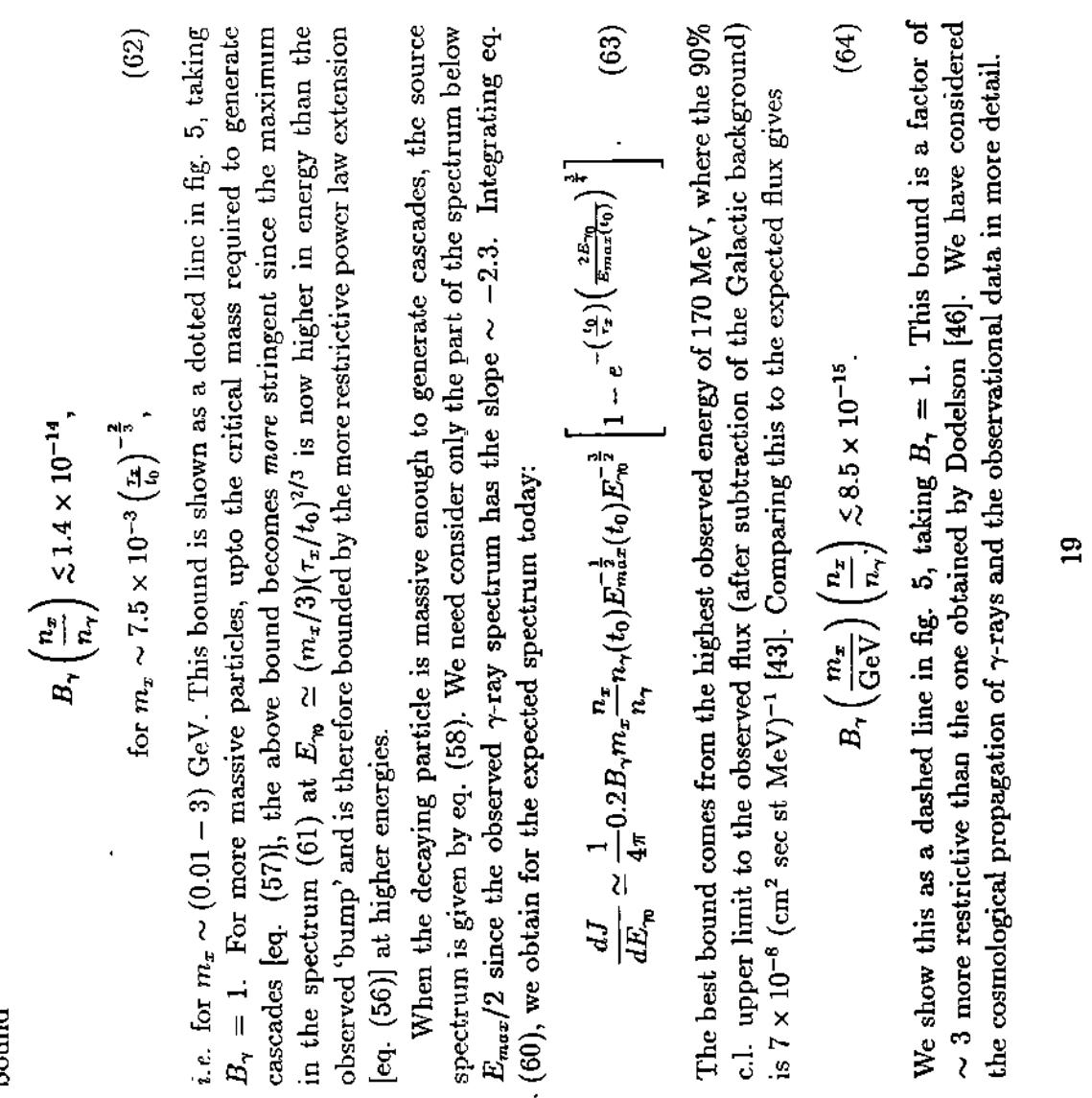




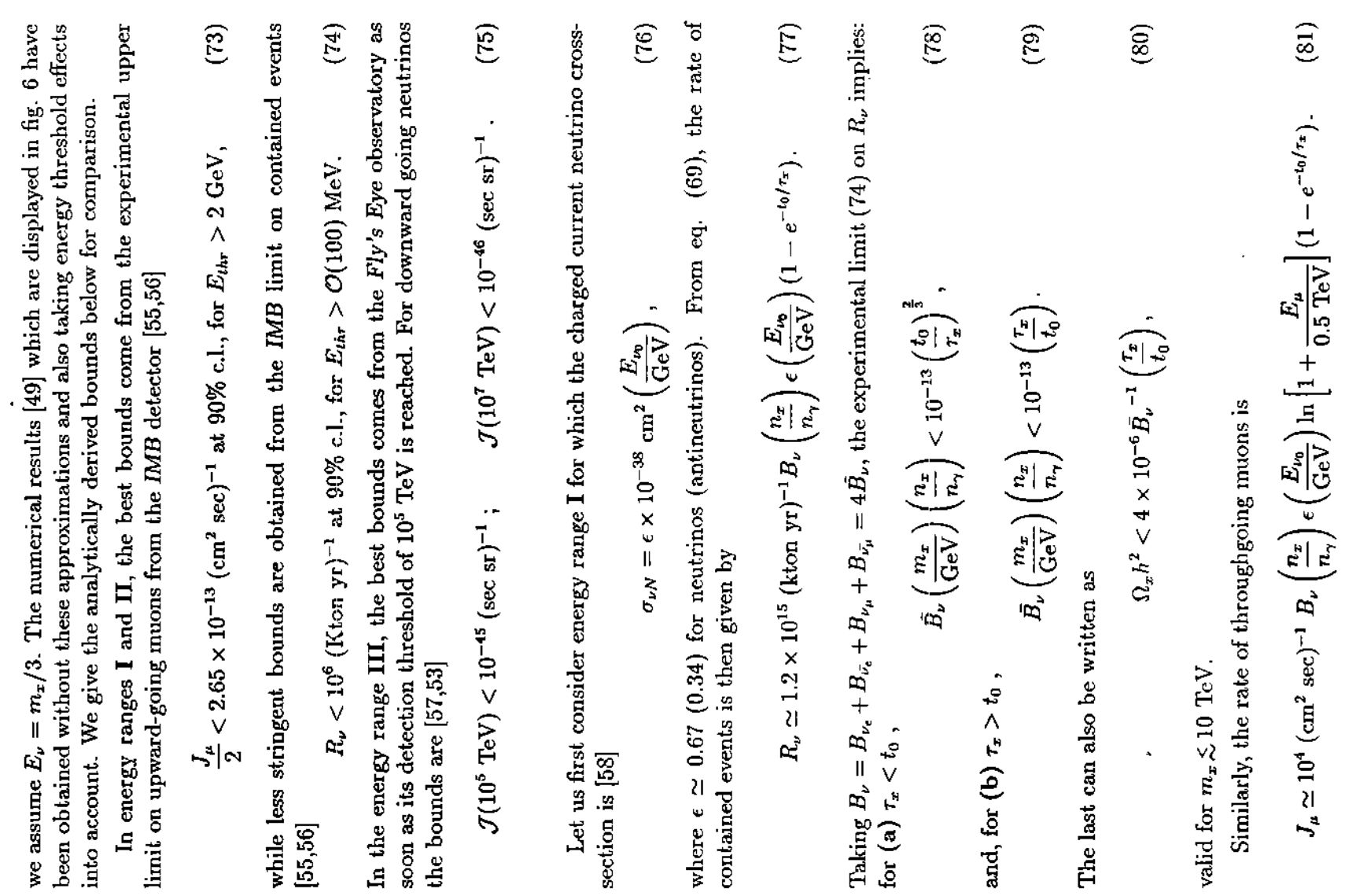

N

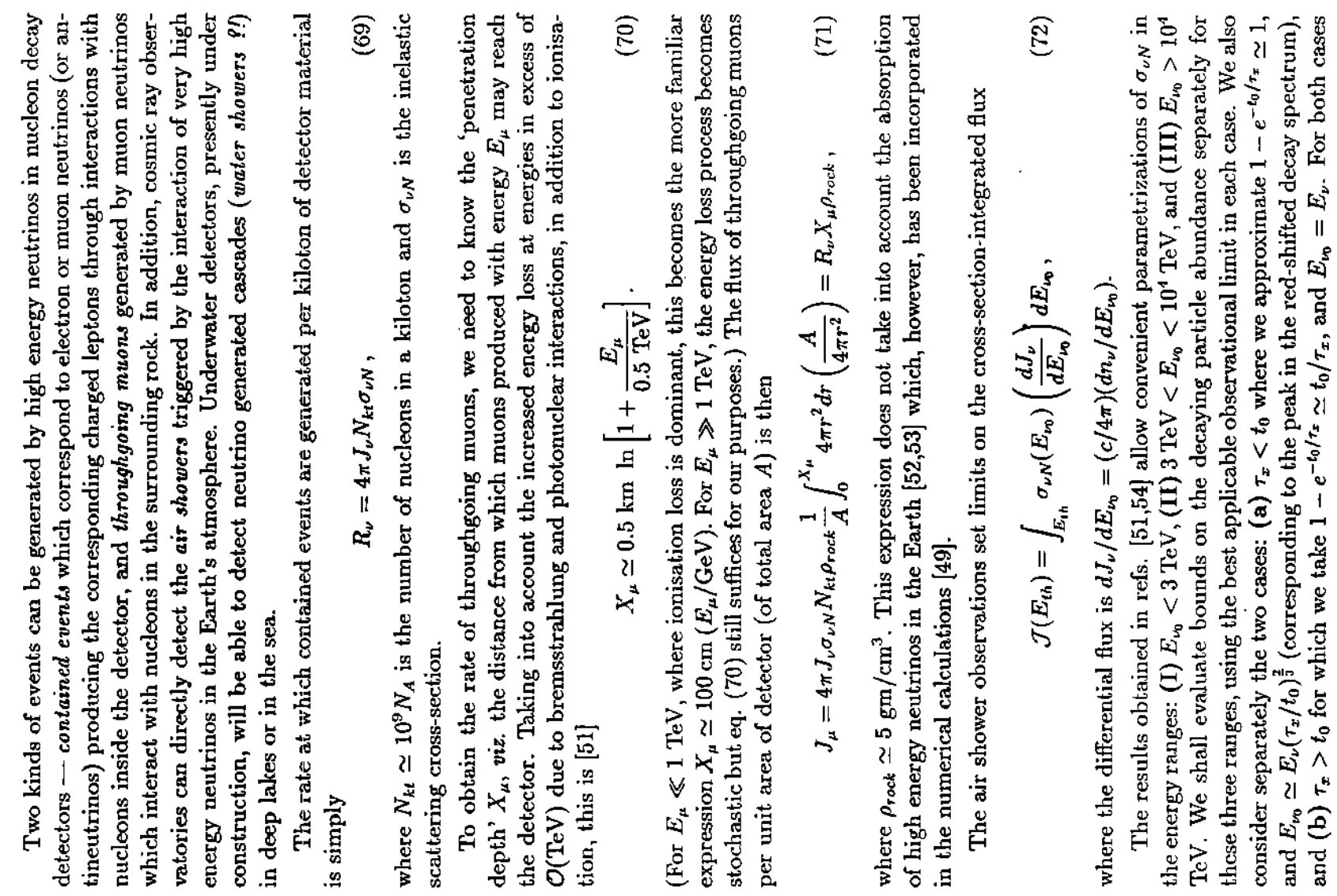




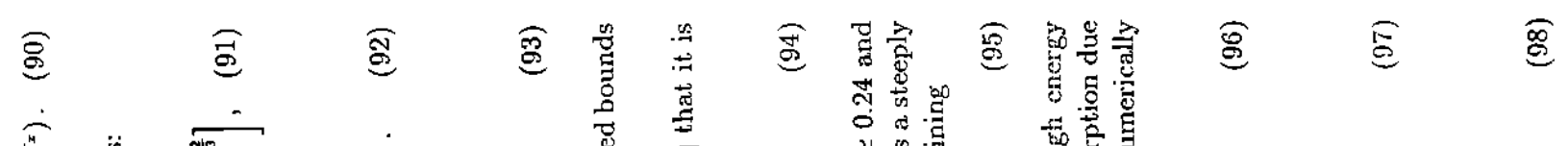

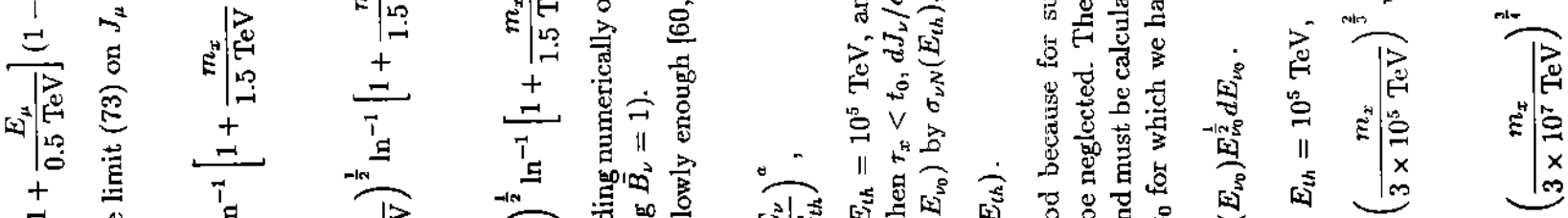
至

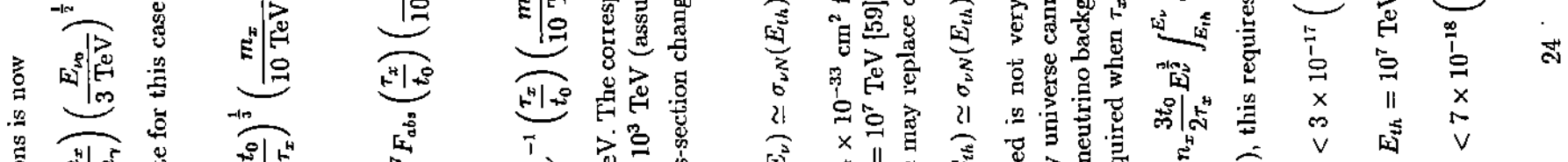

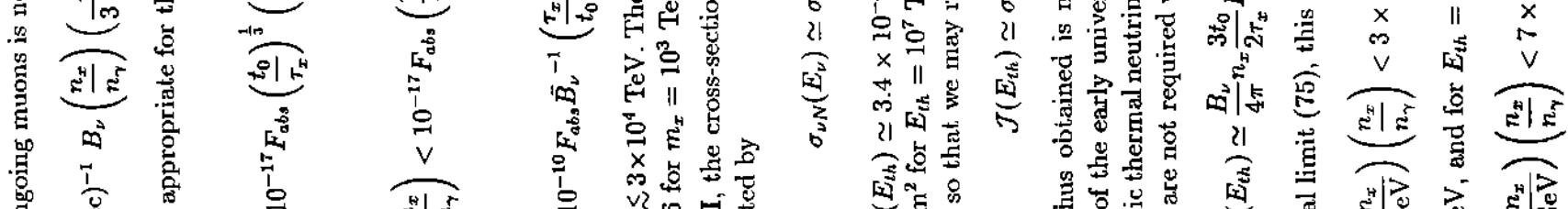

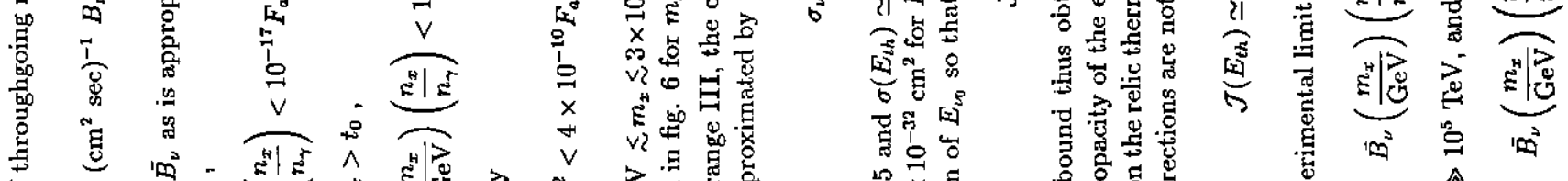

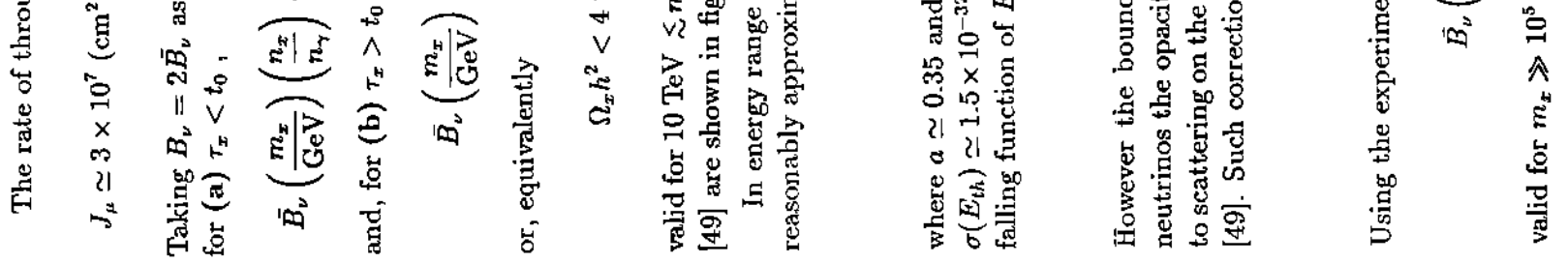

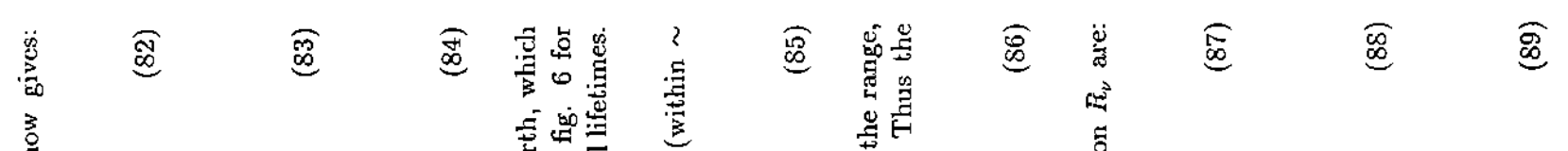
3

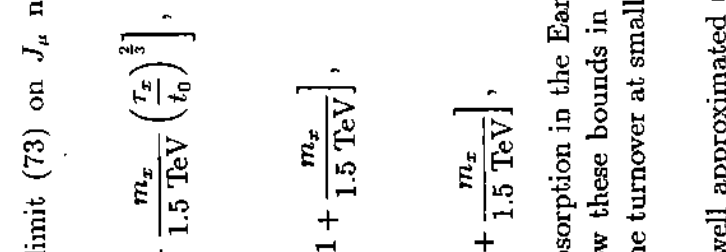

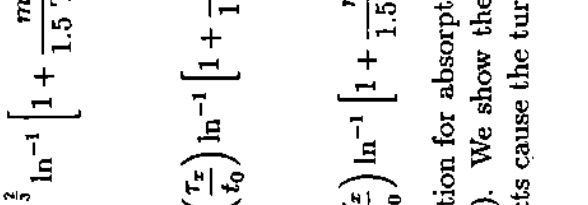

沗

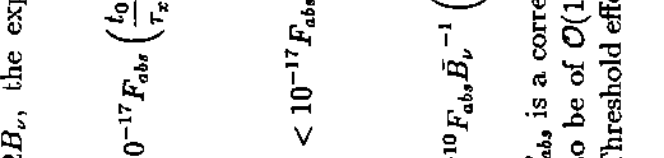

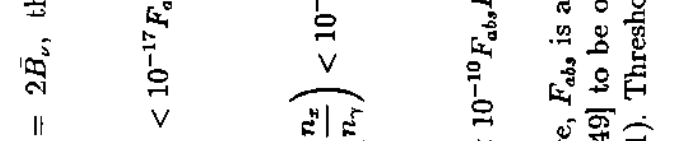

A

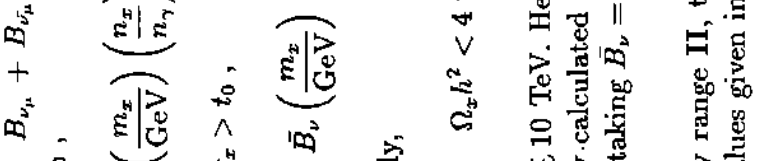

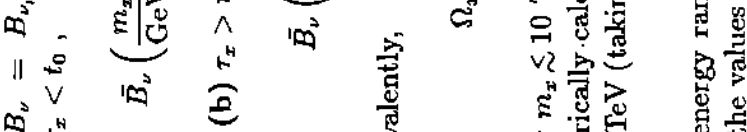

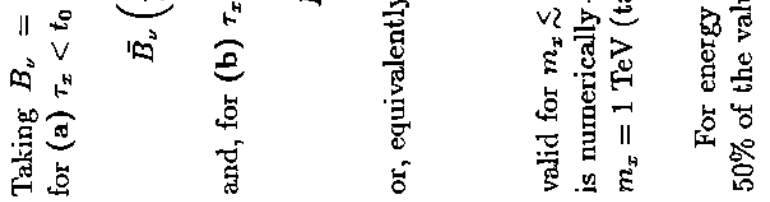

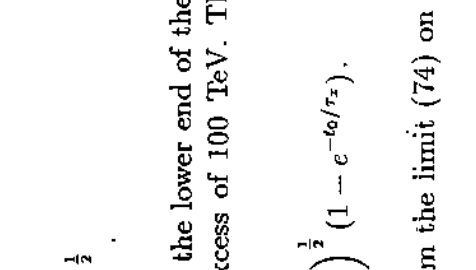

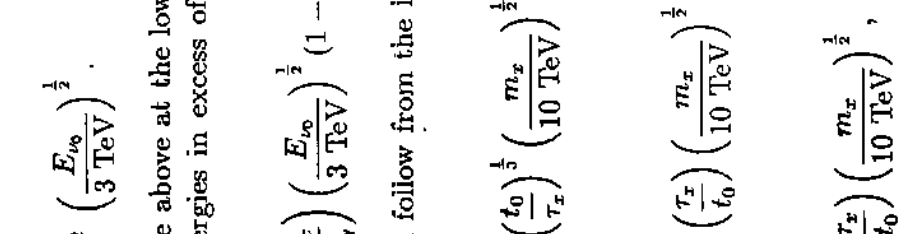

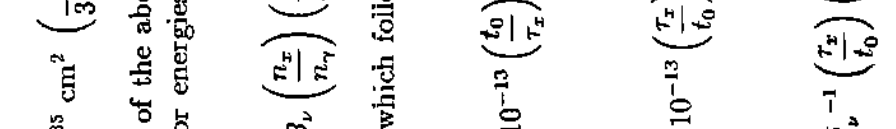

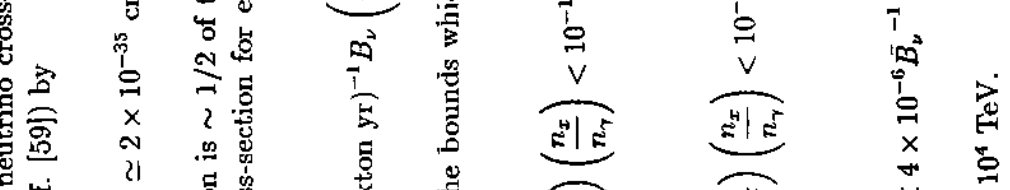

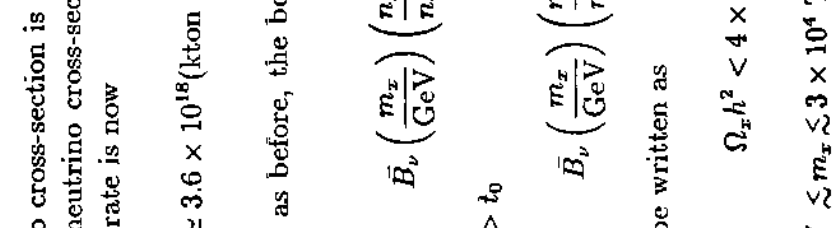

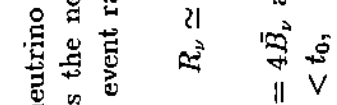

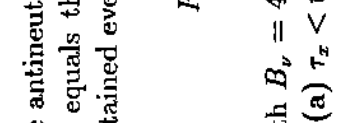

节蓆

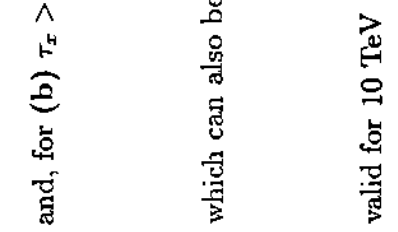




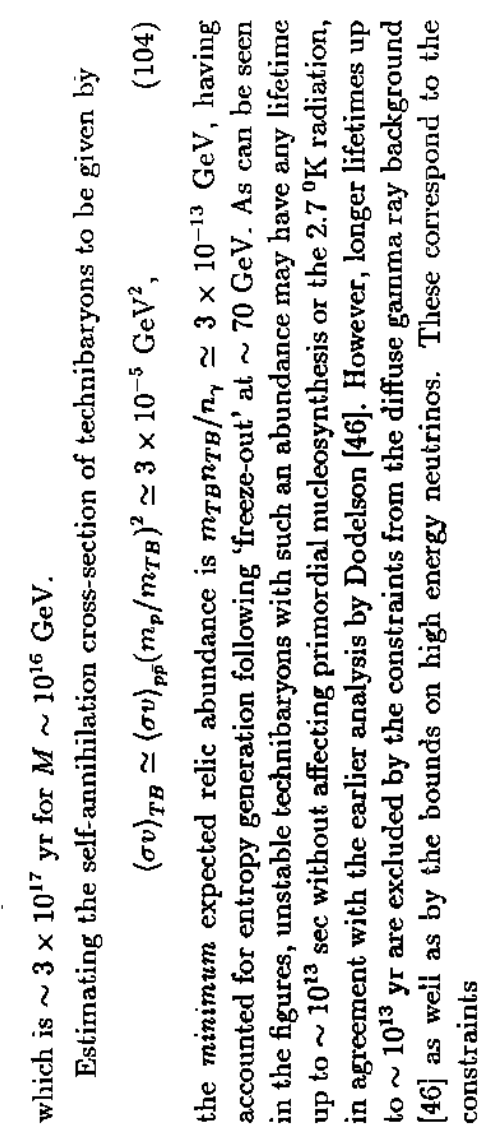

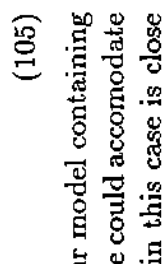

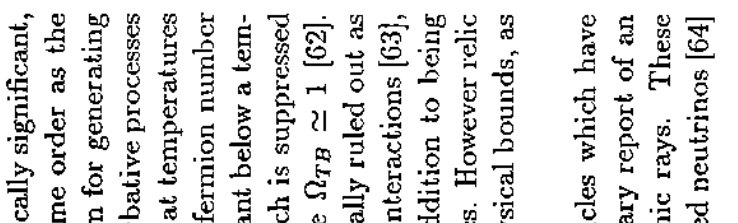

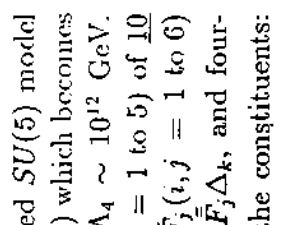

它要要

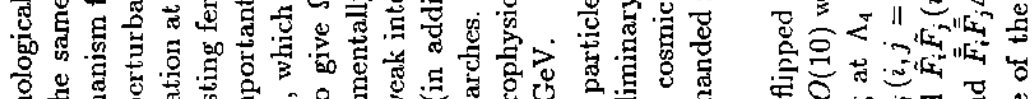

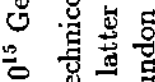

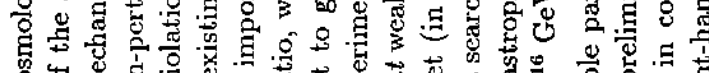

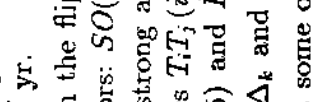

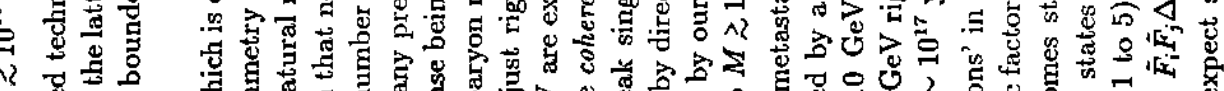

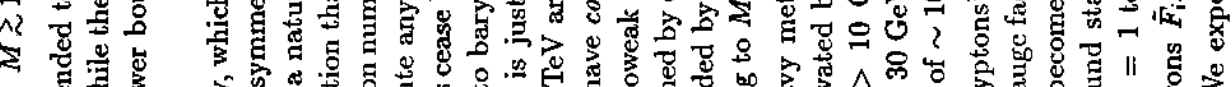

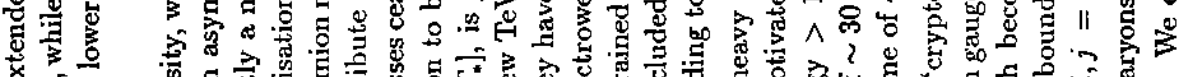

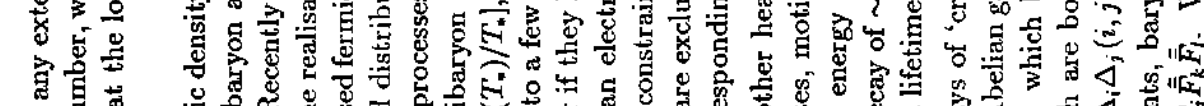

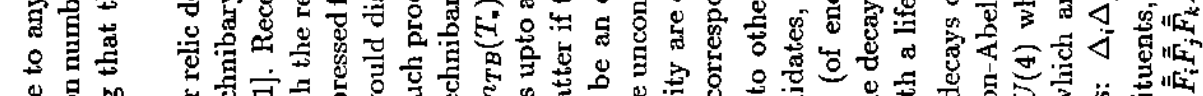

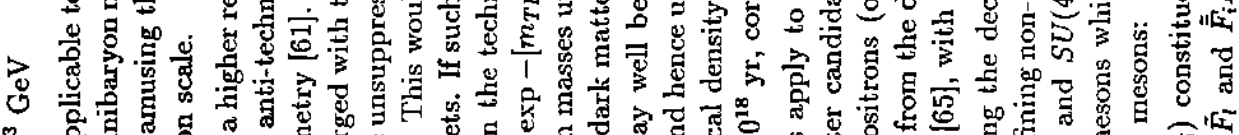

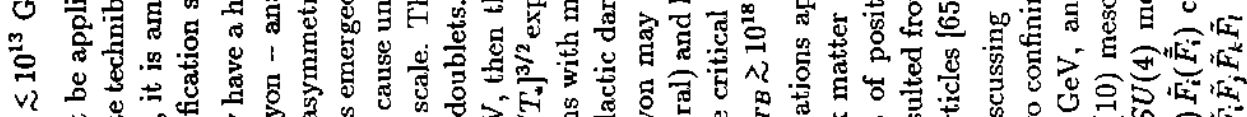
V $\frac{0}{2}$

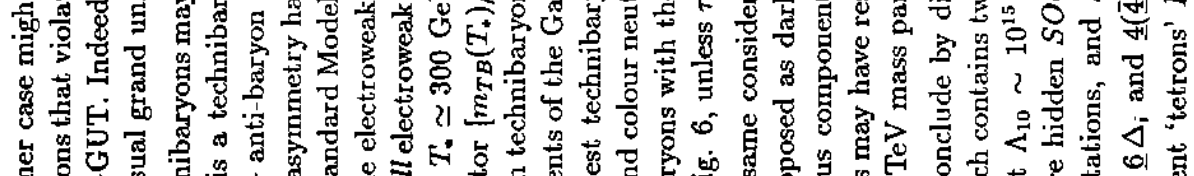

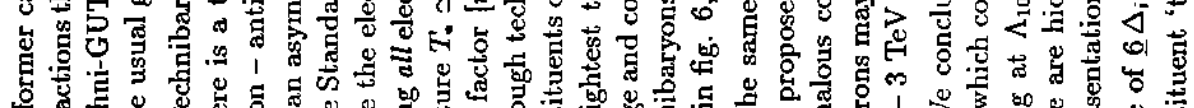

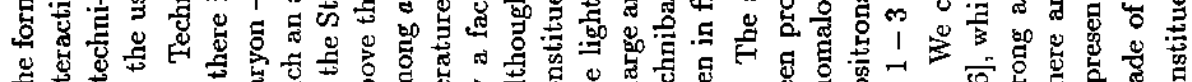

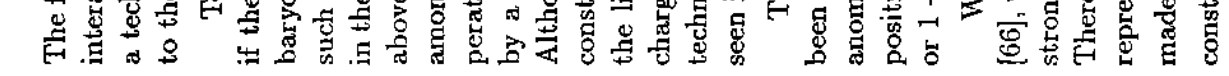

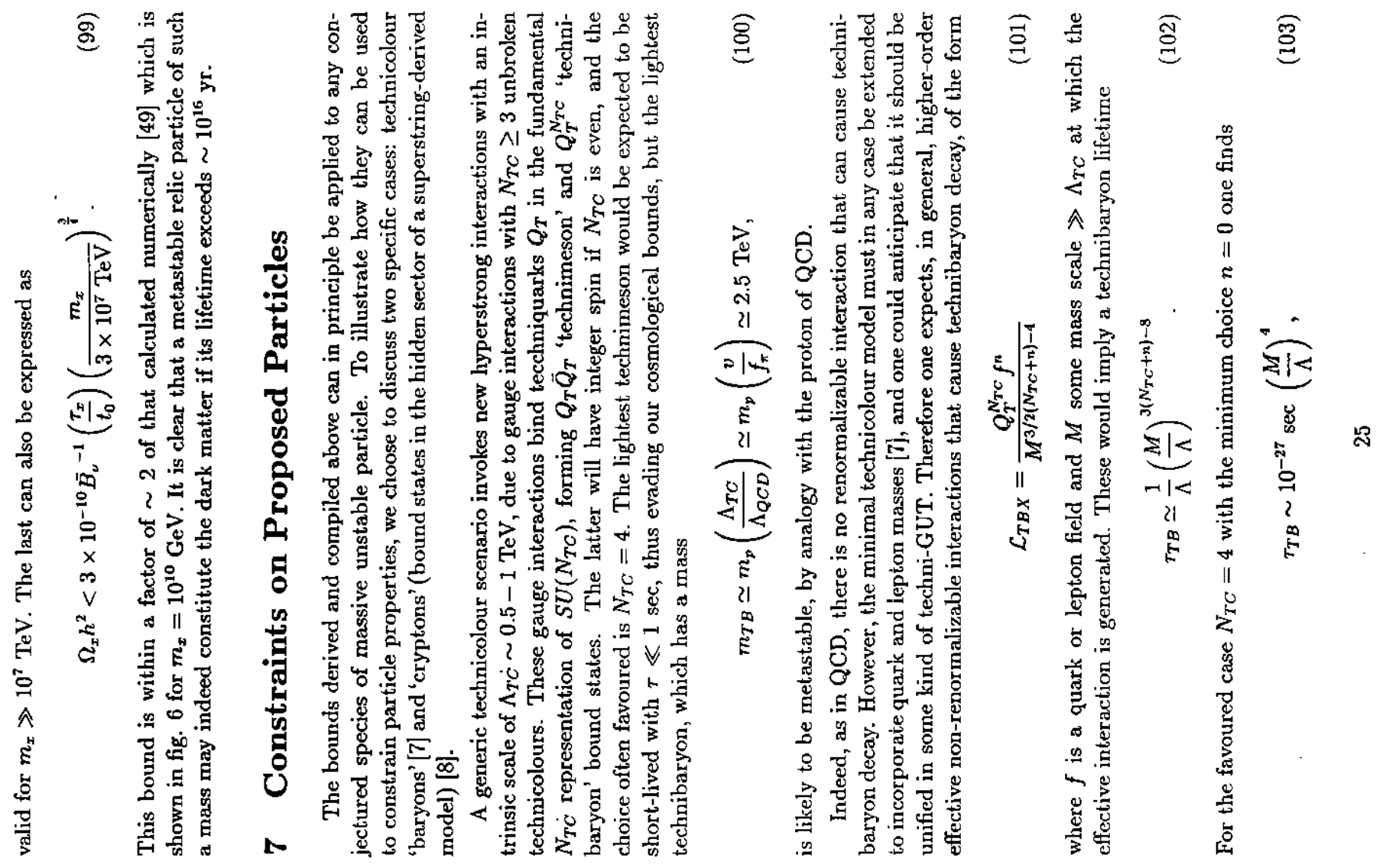




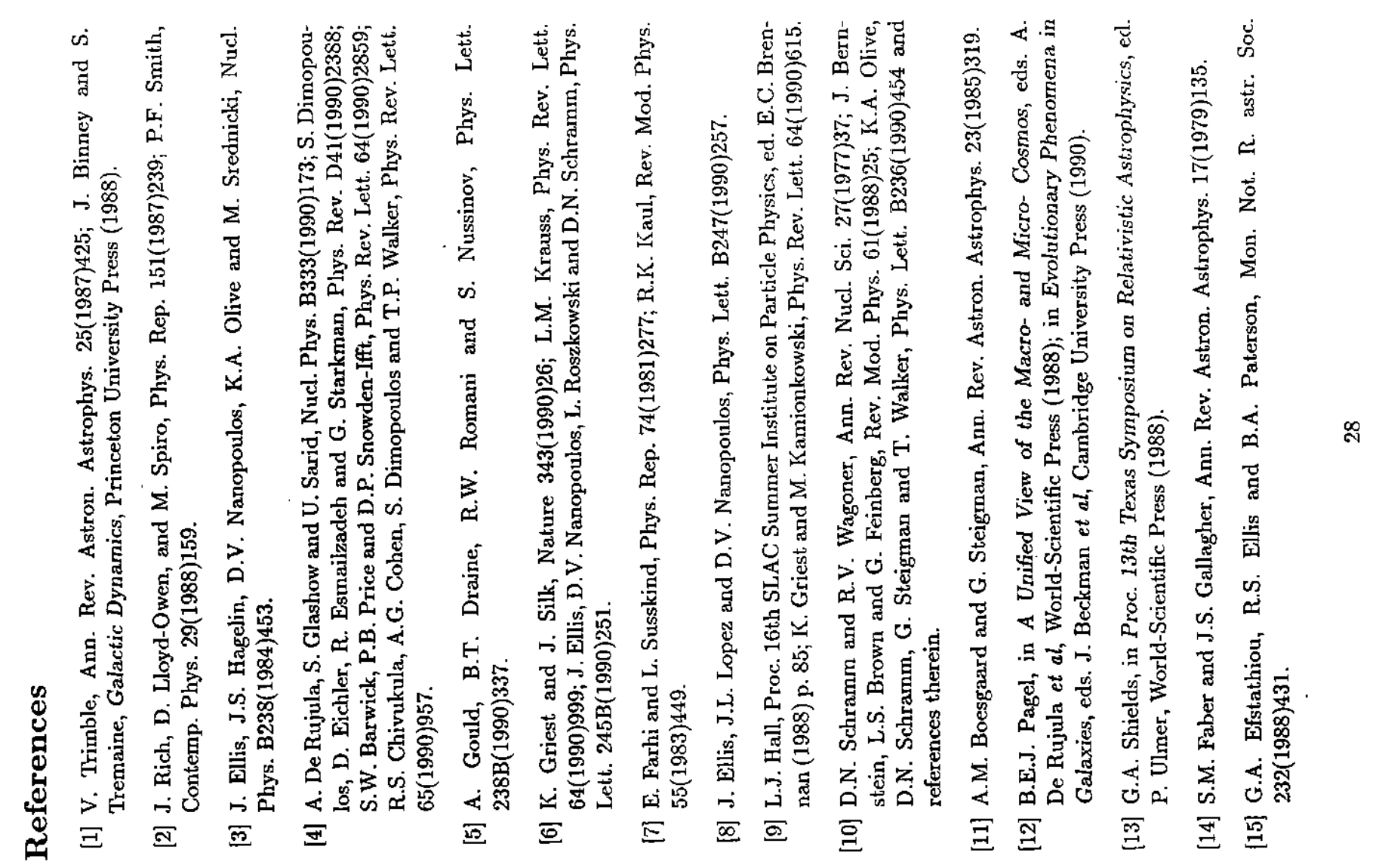

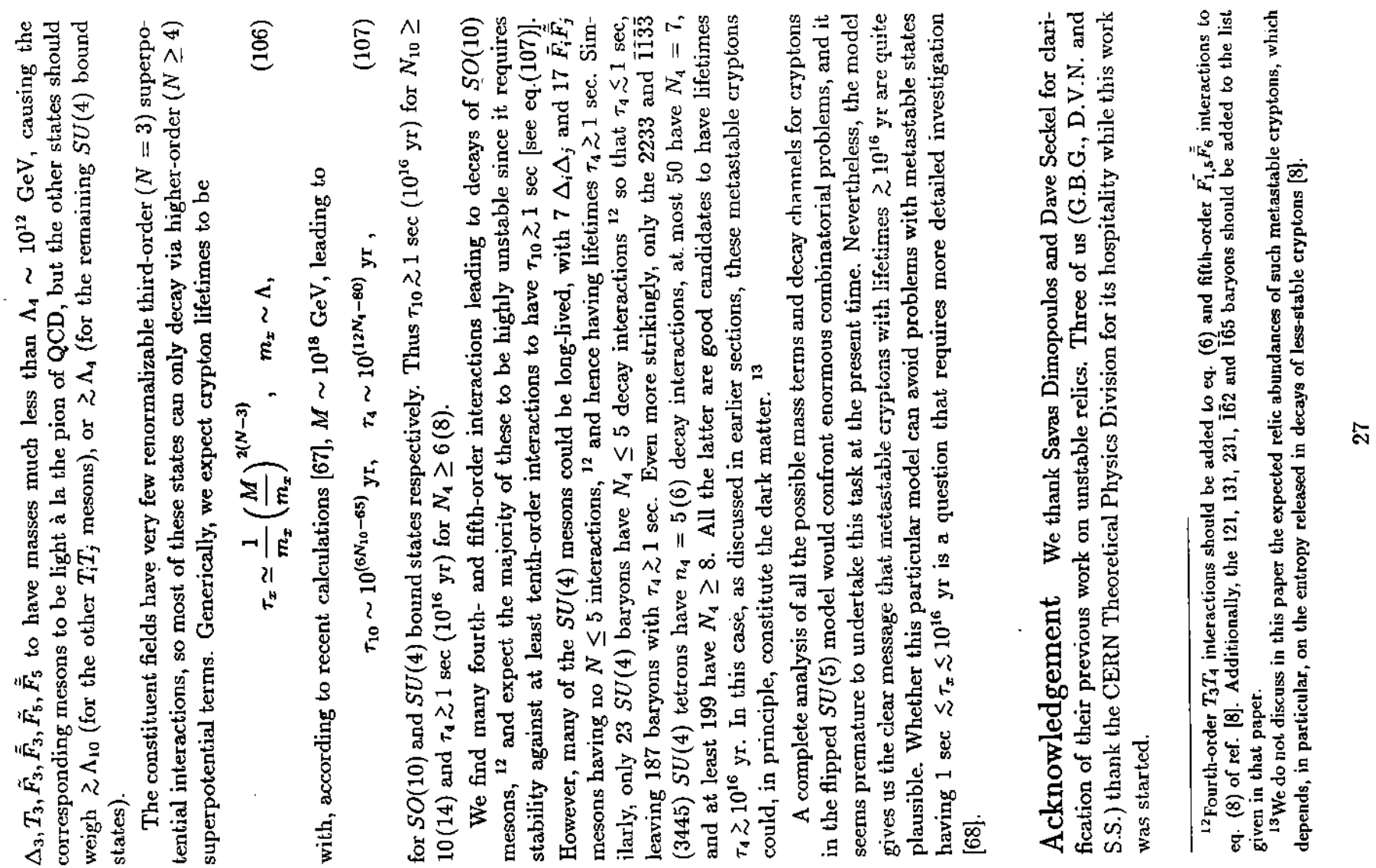



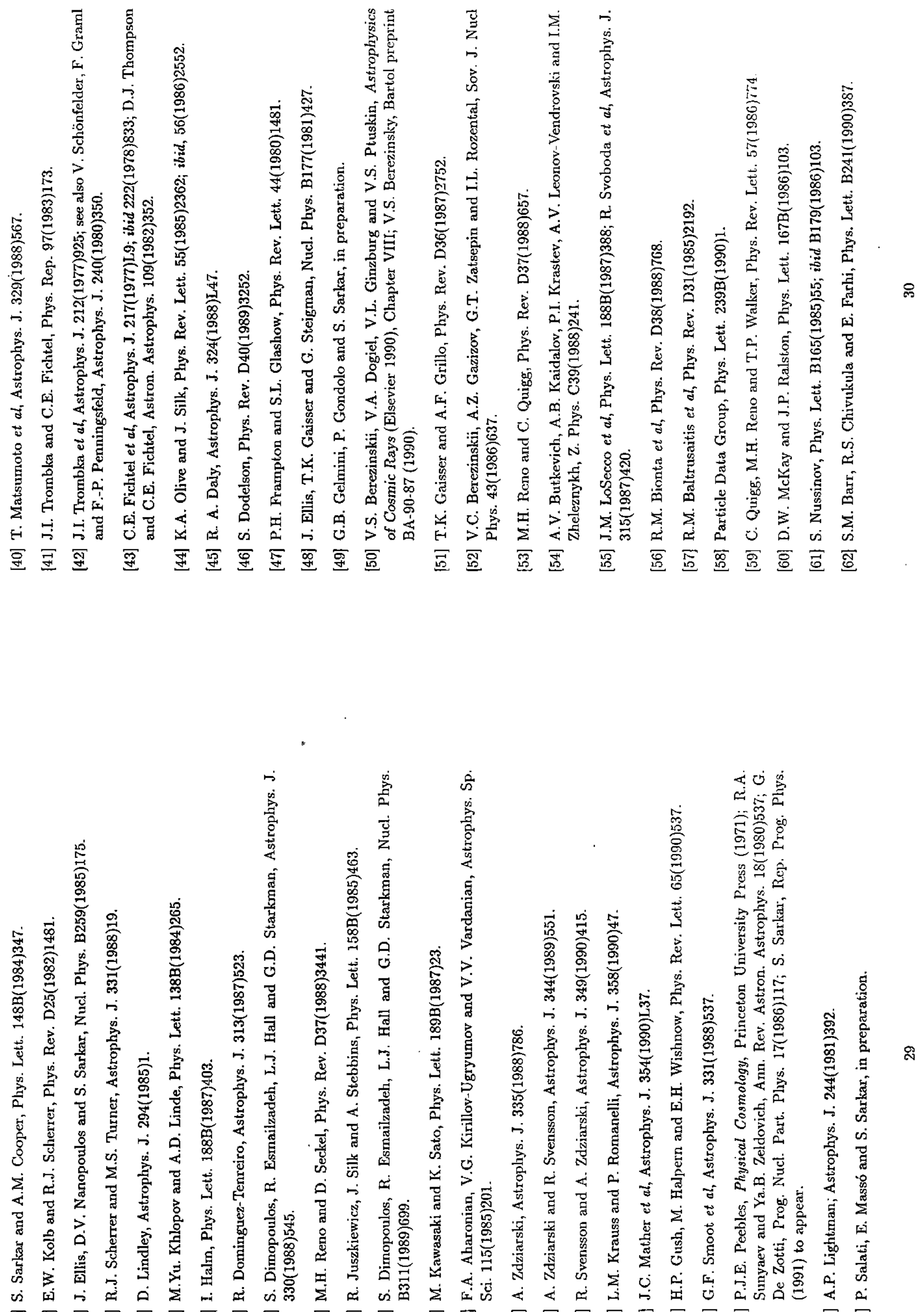

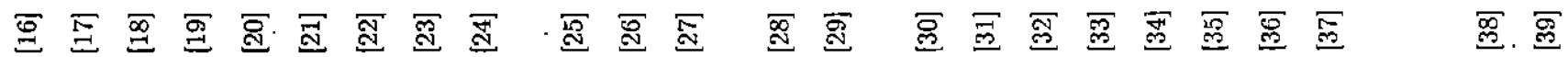




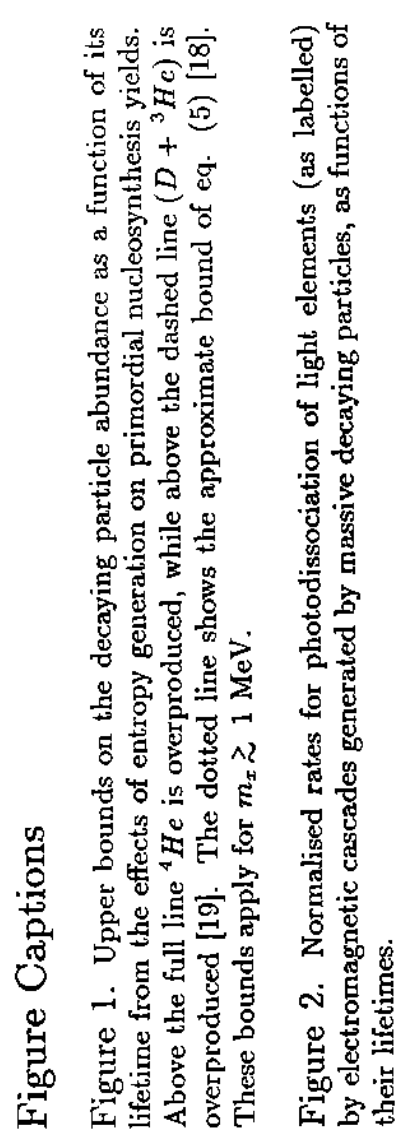

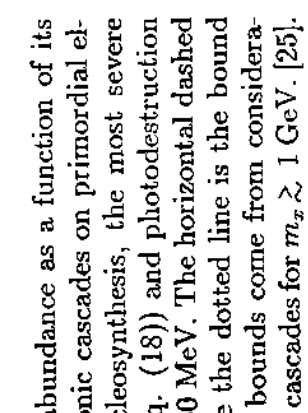

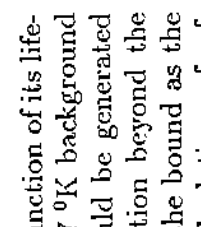

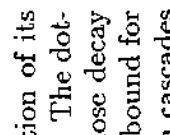

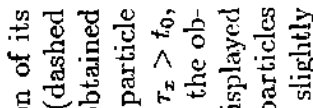

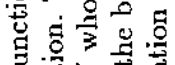

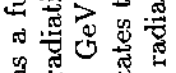

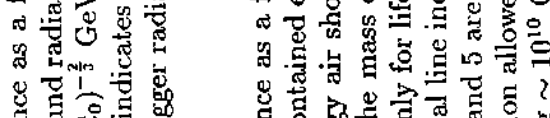

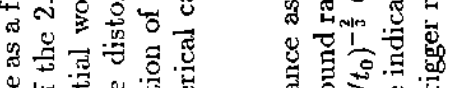

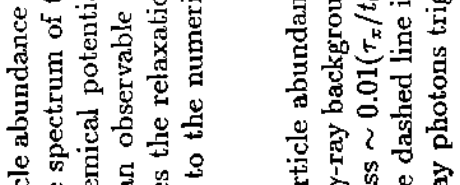

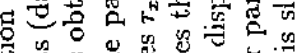

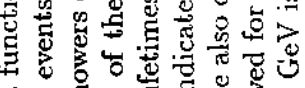

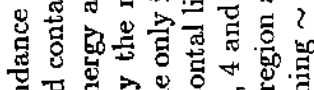

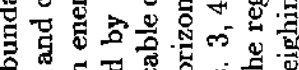

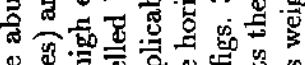

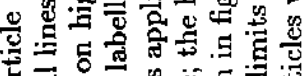

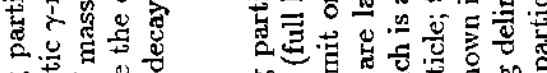

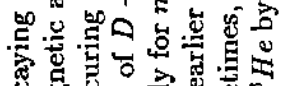

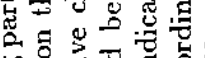

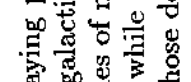

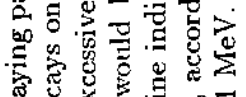

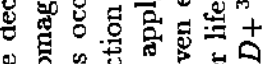

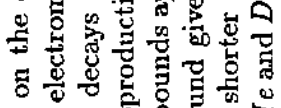

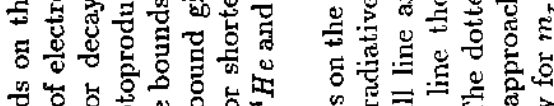

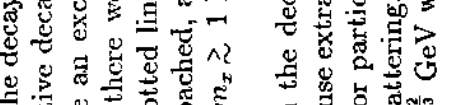

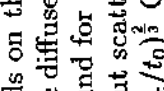

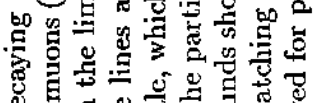

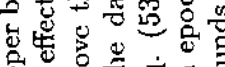

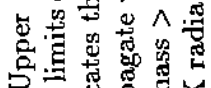

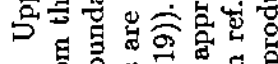

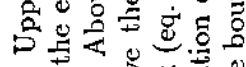
ल

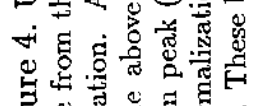

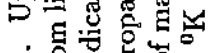
ช

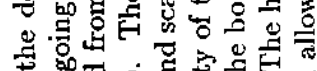

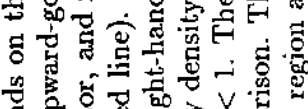

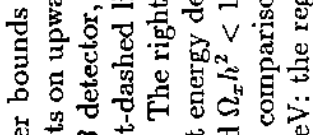

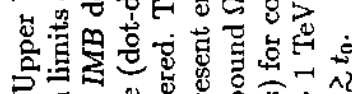

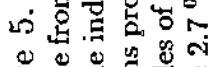

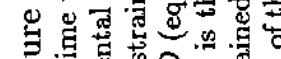

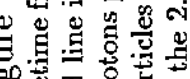

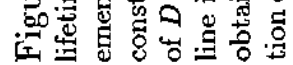

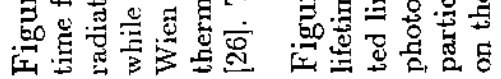

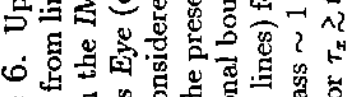

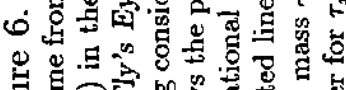

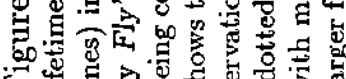

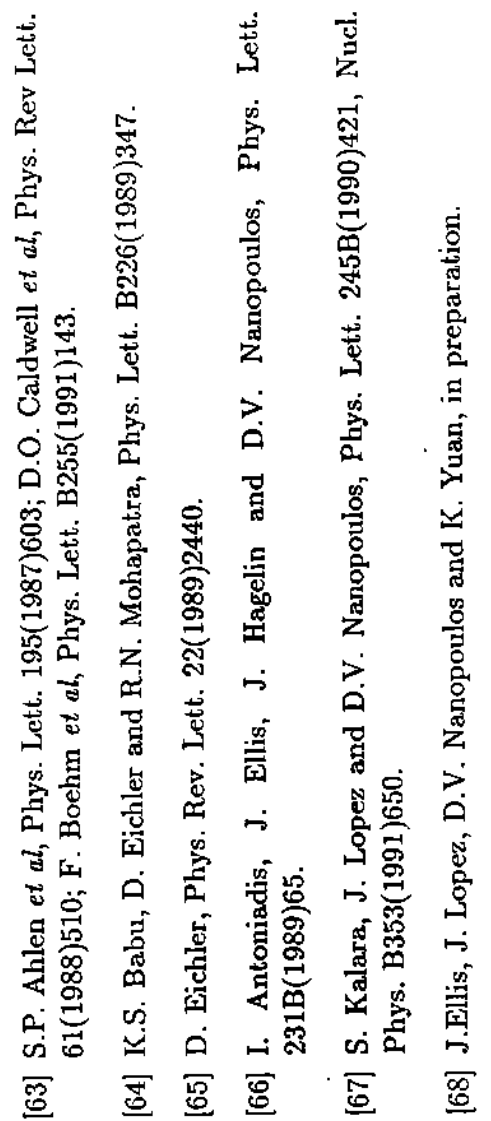




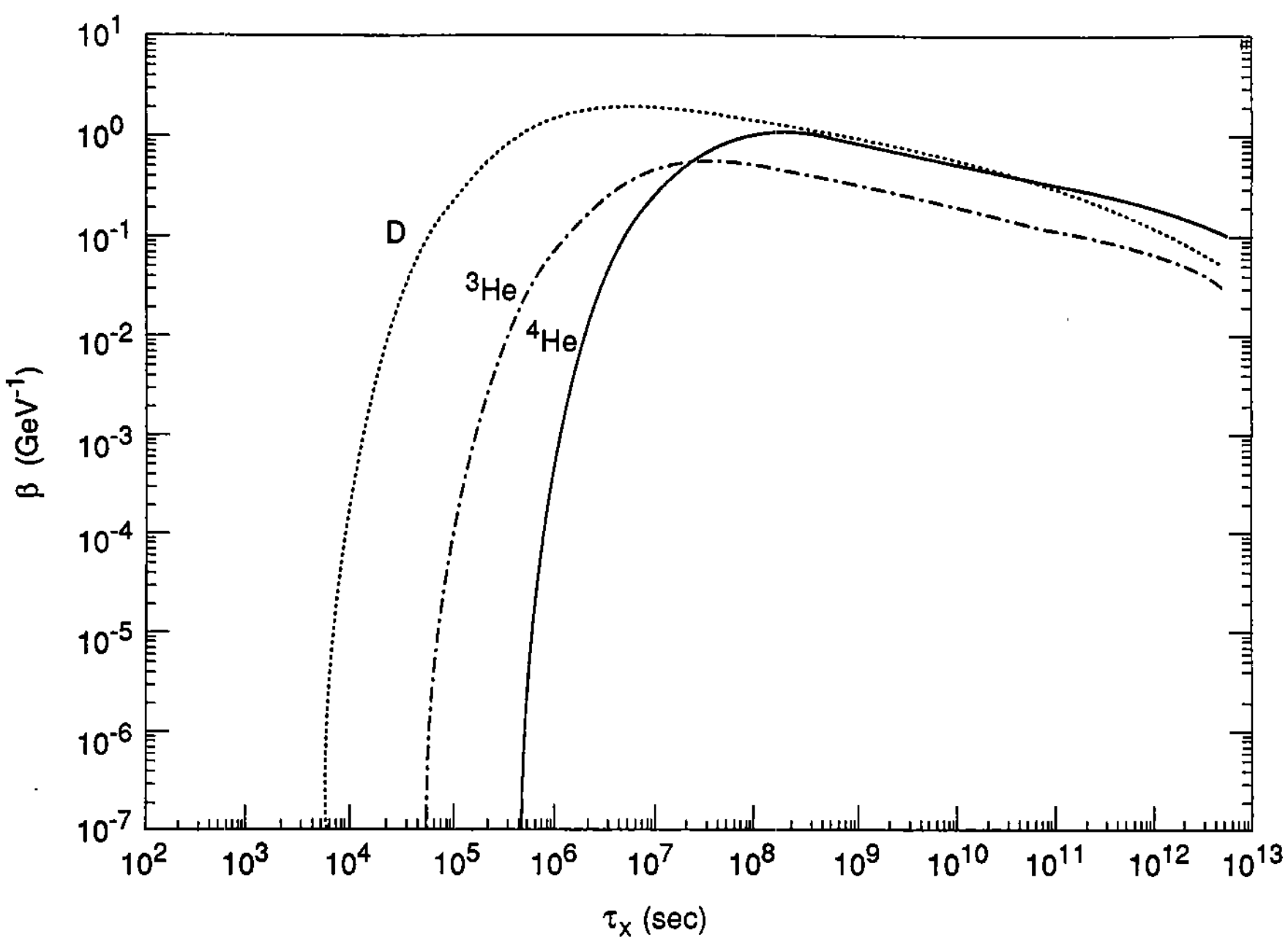

- Figure 2 -

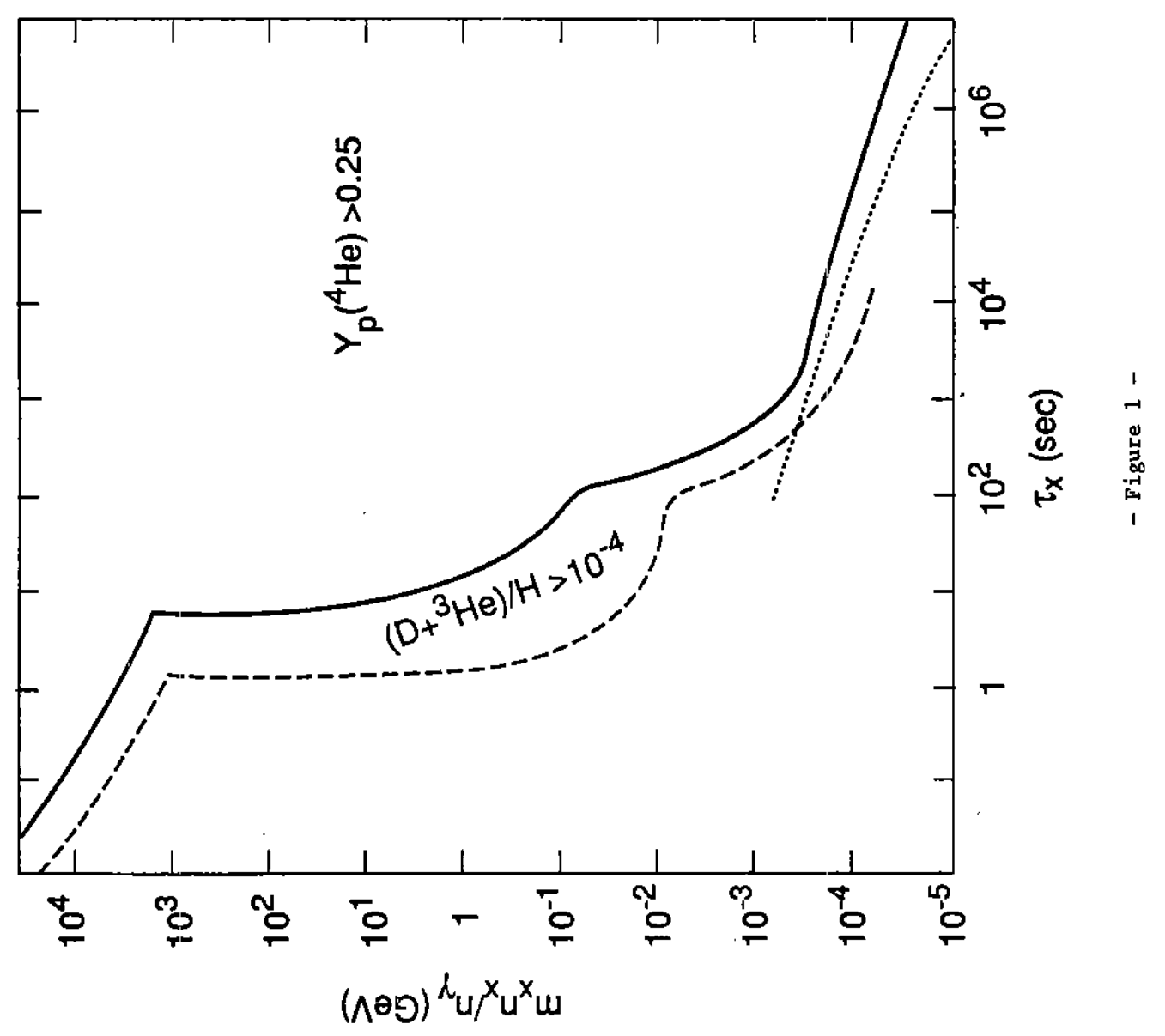



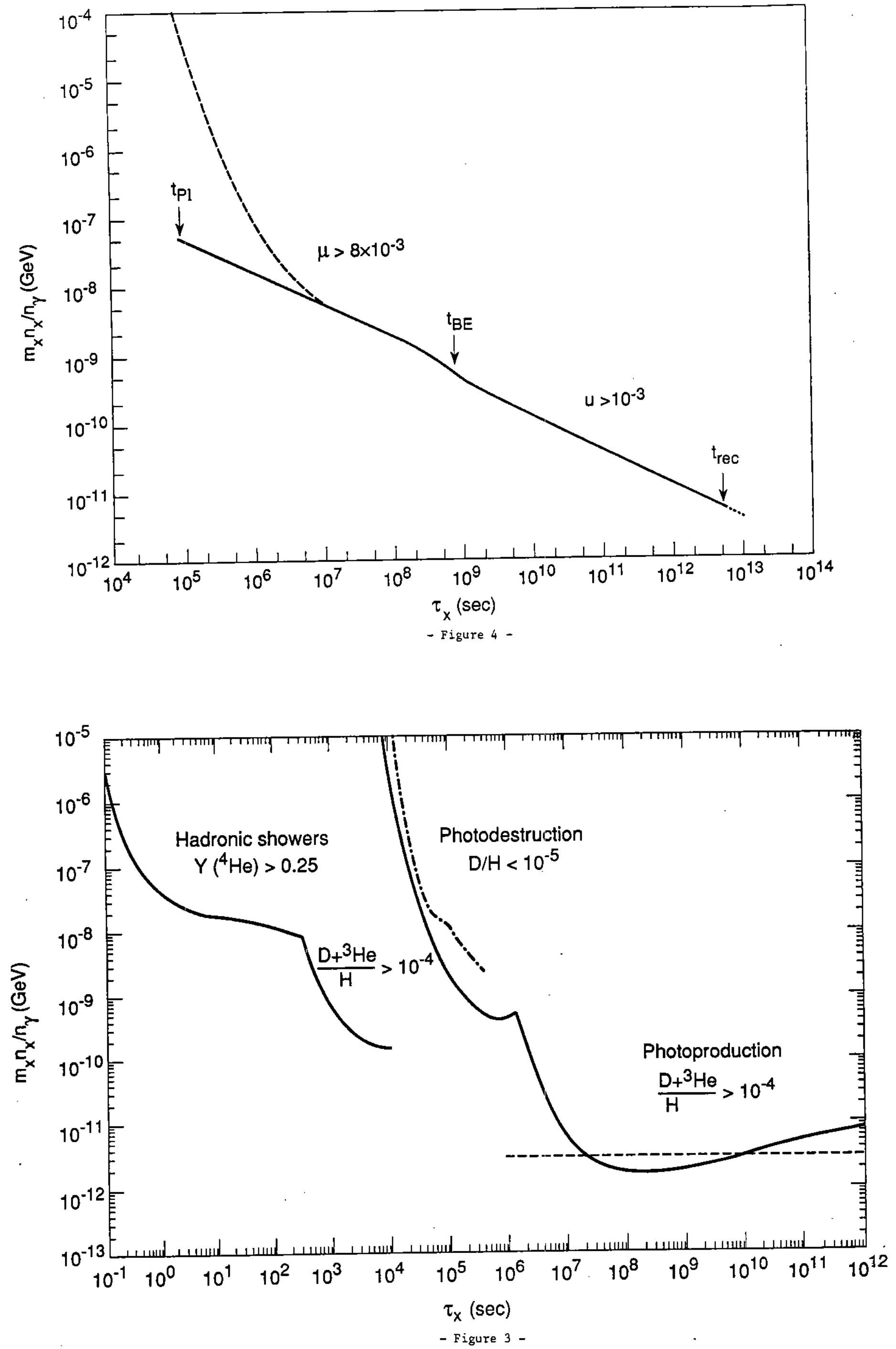


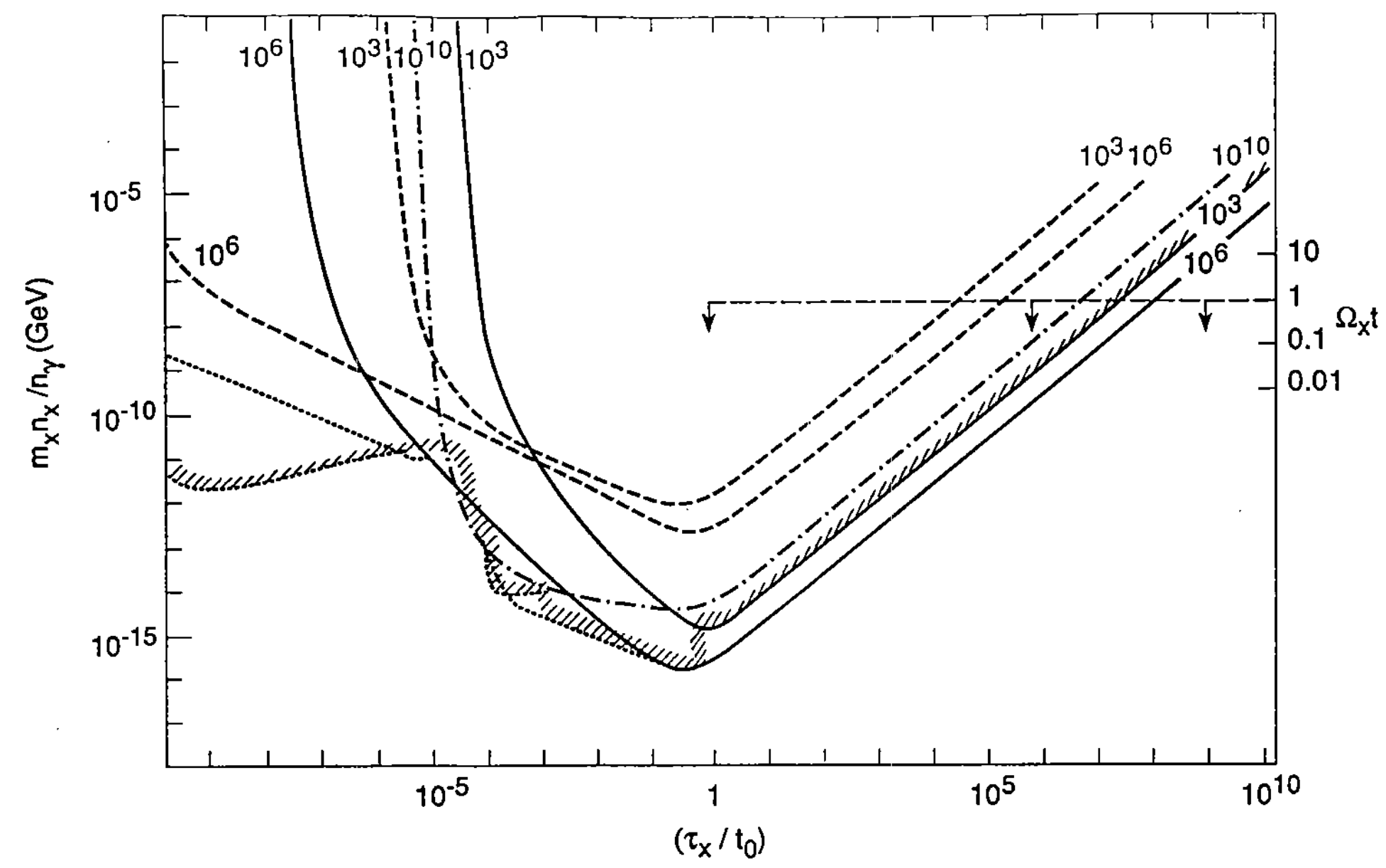

0
0
0
0
0
0

- Figure 6 -

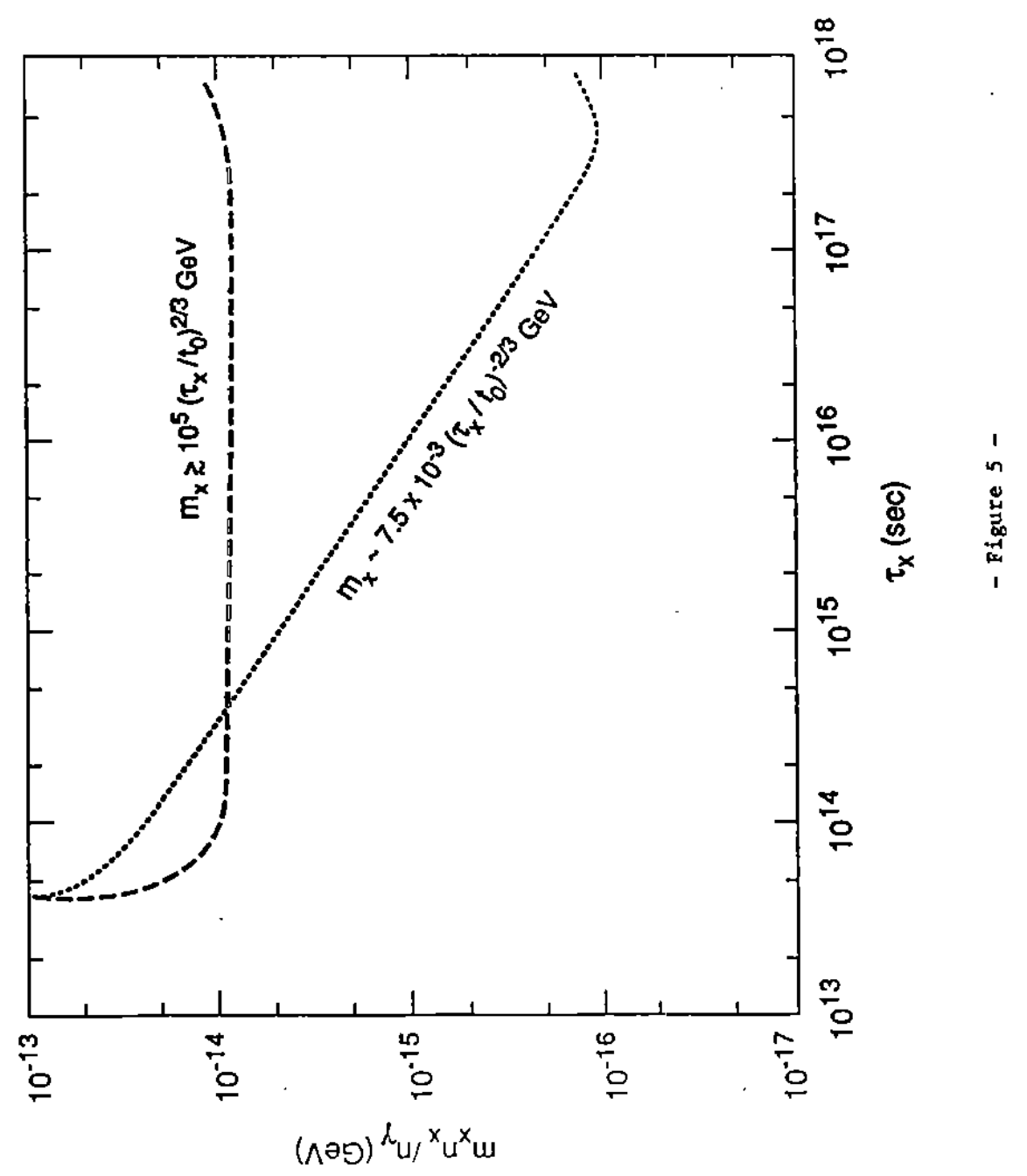

